Scientiæ studia, São Paulo, v. 6, n. 4, p. 461-95, 2008

\title{
st \\ Francis Bacon y el atomismo: una nueva evaluación
}

\author{
Silvia Manzo
}

\begin{abstract}
药
RESUMEN

En la actualidad no hay una interpretación unánime acerca de la teoría de la materia de Francis Bacon. Los desacuerdos giran particularmente en torno al atomismo de Bacon y a sus ideas animistas. En este artículo sostengo que a pesar de que Bacon cambió su visión del atomismo repetidas veces, nunca lo rechazó por completo. Reconstruiré las diversas opiniones de Bacon en orden cronológico para establecer su evaluación final del atomismo y las razones sobre las que la justifica. Debido a que Bacon nunca sostuvo una teoría atomista ortodoxa de la materia identificable con el atomismo griego, en este trabajo definiré el atomismo en sentido amplio como una teoría corpuscular de la materia que establece la existencia de partículas últimas e indivisibles. Siguiendo esta delimitación semántica, es posible distinguir dos posiciones baconianas sucesivas: la primera considera que el atomismo constituye un principio ontológico y causal-operativo; la segunda priva al átomo de su capacidad causal-operativa pero deja intacta su prioridad ontológica. Además, investigaré la cuestión de la coexistencia del atomismo y el pneumatismo en la teoría baconiana, un punto que ha sido abordado por las influyentes interpretaciones de Kargon y Rees. Sin embargo, argumentaré que Bacon no consideró que esas dos doctrinas fuesen incompatibles.
\end{abstract}

Palabras-clave • Francis Bacon. Atomismo. Pneumatismo. Teoría de la materia. Animismo.

Causalidad. Vacío. Alquimia. Movimiento. Movimiento de resistencia.

\section{INTRODUGGIÓN}

En la actualidad no hay una interpretación unánime acerca de la teoría de la materia de Francis Bacon. ${ }^{\mathbf{1}}$ Los desacuerdos giran particularmente en torno al atomismo de Bacon y a sus ideas animistas. Robert Kargon ha afirmado que Bacon abandonó progresiva-

1 Las siguientes abreviaturas serán usadas para designar las obras individuales de Bacon: ANN (Abecedarium novum naturae), ADV (The advancement of learning), CF (A confession of faith), CNR (Cogitationes de natura rerum), DAU (De dignitate et augmentis scientiarum), DGI (Descriptio globi intellectualis), DIN (De interpretatio naturae), DSV (De sapientia veterum), DVM (De viis mortis), HDR (Historia densi et rari), HVM (Historia vitae et mortis), MS (Meditationes sacrae), NO (Novum organum), PHU (Phaenomena universalis), PO (De principiis atque originibus), SS (Sylva sylvarum), TPM (Temporis partus masculus), VT (Valerius terminus). Las referencias a los trabajos de Bacon remiten a Bacon, 18571874. LL se refiere a The letters and life of Francis Bacon (Bacon, 1861-1874). Todas las traducciones al español son mías. 
mente su teoría temprana del atomismo y la reemplazó por una teoría pneumática de la materia opuesta a ella. Graham Rees ha ido aún más lejos al sostener que Bacon nunca se comprometió firmemente con el atomismo, el cual sólo jugó un rol metodológico, por ejemplo, en su invocación del método democriteano de disección de la naturaleza para descubrir su sutilidad. Rees también postula que el pneumatismo baconiano fue el único sustento de su denominada teoría semi-paracelsiana de la materia. Por otra parte, un punto de vista diferente sugiere que, a pesar de que Bacon cambió su visión del atomismo repetidas veces, nunca lo rechazó por completo (cf. Partington, 1961; Urbach, 1987). La relevante investigación de Benedino Gemelli parece corroborar esta última perspectiva. Haciendo foco en la relación de Bacon con el atomismo clásico y sus fuentes, Gemelli concluye que, si bien Bacon rechazó el vacío, el átomo representaba para él la unidad mínima de la materia, aunque no desempeñara ningún papel central en su programa experimentalista (cf. Kargon, 1966, p. 37-45; Rees, 1975, 1980; Urbach, 1987, p. 72-9; Partington, 1961, 2, p. 394-6; Gemelli, 1996, p. 195).²

Adhiero a esta segunda interpretación e intentaré fortificarla investigando las razones por las cuales Bacon cambió de opinión acerca del atomismo en el Novum organum y atendiendo particularmente a sus obras alegóricas, que suelen ser pasadas por alto. Reconstruiré las diversas opiniones de Bacon en orden cronológico para establecer su evaluación final del atomismo y las razones sobre las que la justifica.

\section{UNA BUENA HIPÓTESIS}

Bacon fue una de las primeras grandes figuras de la modernidad temprana inglesa que se interesó seriamente por el atomismo antiguo y que examinó su posible utilidad para la nueva ciencia. Al igual que muchos otros buscó reemplazar la filosofía natural de corte aristotélico, que rechazó en repetidas oportunidades, por una filosofía compuesta de doctrinas extraídas de fuentes del atomismo antiguo y reciente. Un estudio cuida-

\footnotetext{
2 Las posturas de Lasswitz (1963 [1891], p. 413-6) y Hesse (1983) son en cierta medida similares a la de Kargon. Macció (1962) afirma que el abandono del atomismo por parte de Bacon no se derivó de su teoría de las formas ni de su teoría pneumática de la materia, sino que se debió a la explicación del movimiento corpuscular a partir de las causas segundas. Rossi (1990 [1974], p. 194-7, 221-8) sostiene que Bacon adoptó en principio el atomismo y luego lo rechazó aunque nunca consideró que existiera incompatibilidad alguna con perspectivas animistas, e incluso sugiere que Bacon no estaba convencido de que la ciencia fuera capaz de investigar los principios de la realidad. Jardine (1974, p. 114) pone de relieve la indecisión de Bacon en torno al atomismo. Pérez-Ramos (1988, p. 102, nota 8) piensa que la respuesta no decisiva de Bacon al atomismo no es importante para nuestra comprensión de la "sintaxis" de sus posturas ontológicas. No obstante, considero que el concepto de forma puede ser comprendido mejor si se cuenta con una visión más clara acerca de su teoría de la materia.
} 
doso de la reacción de Bacon hacia el atomismo puede ayudarnos a reconstruir cómo se recuperó esta doctrina en la primera etapa de la revolución científica. Además de la influencia indudable de las fuentes antiguas que Gemelli se ha encargado de rastrear con sofisticación filológica, es necesario mencionar la relación de Bacon con autores contemporáneos interesados en las teorías atomistas. Existen evidencias del vínculo de Bacon con miembros del Círculo de Northumberland. Sabemos que tenía contacto directo con William Lower, ${ }^{3}$ el discípulo de Harriot y amigo del conde de Northumberland, a quien conoció en 1603, y con William Percy, a quien le escribió una carta ese mismo año celebrando el interés científico de Percy (cf. Kargon, 1966, p. 43-4). Harriot, Raleigh y el conde de Northumberland son mencionados en las notas personales de Bacon de 1608 y descriptos como valiosos aliados de su programa de restauración de la ciencia (LL, 3, p. 58; LL, 4, p. 63). Es muy probable que Bacon tomara conocimiento del atomismo a través de su contacto con el Círculo de Northumberland, dado que la primera vez que menciona esta doctrina lo hace en la época en que conoció a Lower. Giordano Bruno debe haber sido otra influencia importante en él. Bruno permaneció en Inglaterra entre 1583 y 1585 , y se decía que había inspirado a algunos miembros del Círculo de Northumberland con sus perspectivas atomistas (cf. Kargon, 1966; Jacquot, 1974; Gatti, 1983, 1985). A pesar de que encontramos algunos indicios de la caracterización bruniana del atomismo pitagórico en la obra de Bacon, no existe evidencia alguna de que hubiera estado al tanto de las teorías atomistas del italiano.

El interés de Bacon en el modelo atomista se manifiesta por primera vez en sus Cogitationes de natura rerum (ca. 1604), donde el atomismo es valorado como una buena hipótesis para explicar la sutilidad de la naturaleza, siendo por consiguiente "verdadera o útil para la demostración" (CNR, 3, p. 15). En esta etapa, Bacon acepta el atomismo como un instrumento heurístico. Más allá de que la hipótesis fuera falsa o no, lo importante radicaba en que se trataba de una buena hipótesis. A lo largo de este período, Bacon está convencido de que la ciencia debe buscar las entidades y los movimientos mínimos o "sutiles" escondidos en la naturaleza (cf. Wolf, 1910-1913, 1, p. 274; TPM, 3, p. $5^{3} 7$ ). La compleja idea que tenía de la naturaleza de la "sutilidad" guardaba similitud con la de Cardano. 4 Para este autor, la "sutilidad" operaba a distintos niveles: en primer lugar, era un proceso intelectual por el cual las cosas sensibles eran percibidas por los sentidos y las cosas inteligibles lo eran por el entendimiento, mediante procesos no exentos de dificultad. Pero la "sutilidad" también existía en las

3 Carta de William Lower a Thomas Hariot de julio de 1610 (cf. Rigaud, 1833, p. 68-9).

4 Rees (1980, p. 568) ha sugerido que Cardano fue una posible influencia de la noción baconiana de sutilidad. Es probable que Bacon leyera De subtilitate de Cardano durante sus estudios en el Trinity College. Menciona a Cardano explícitamente en DAU, , p. $45^{6}$ y TPM, 3, p. 530, $57^{\circ}$. 
sustancias mismas, en sus accidentes y representaciones (imágenes, especies, discursos, escritos). En las sustancias corpóreas la sutilidad se asociaba con la pequeñez, la fluidez y la divisibilidad, mientras que en las sustancias incorpóreas se vinculaba con los secretos de Dios y el orden del universo. En cuanto a los accidentes causados externamente, la idea de sutilidad de Cardano era más variada e incluía máquinas artificiales sofisticadas, así como acrósticos, enigmas y problemas matemáticos. Dada esta clasificación, la sutilidad intelectual inevitablemente se convierte en la sutilidad del objeto en sí. La sutilidad le pertenece tanto al objeto como al sujeto sensible e inteligente (cf. Cardanus, 1554, p. 1-2; Eamon, 1994, p. 279-81).

Muchos de los sentidos cardanianos de sutilidad se pueden encontrar en la obra de Bacon, quien habla de ella como un atributo objetivo que atañe a la naturaleza en general (CNR, 3, p. 15-7; NO, 1, p. 154, 184, 3०6, 3०9), que no sólo se encuentra en texturas y esquematismos materiales, en movimientos y metaesquematismos, sino también en productos del arte como los relojes, que pueden ser tan sutiles como los productos de la naturaleza. En fin, los más grandes resultados de las distintas artes liberales y de las ciencias son admirados por su gran sutilidad (cf. NO, 1, p. 168, 191-2, 259, 266; HVM, 2, p. 197). Para Bacon, al igual que para Cardano, la sutilidad se refiere a la extrema pequeñez o imperceptibilidad (es decir, invisibilidad e intangibilidad) (cf. NO, 1, p. 3०6-9, 318, 333; VT, 3, p. 238; DVM, p. 18v; HVM, 2, p. 195-6; SS, 2, p. 38o-2; CNR, 3, p. 3o). El concepto se refiere tanto a la materia tangible como a la pneumática, ya que ambas son imperceptibles a nivel corpuscular (cf. NO, 1, p. 311).5 En el Novum organum las denominadas instancias cortantes (también llamadas "instancias de Demócrito") son designadas para recordar al lector la extrema sutilidad de la naturaleza: una gota de tinta se esparce en muchas líneas y letras; una pizca de algalia perfuma un volumen de aire mucho mayor etc. (cf. NO, 1, p. 319-20). Bacon tiene particular predilección por el ejemplo de la disolución del azafrán en el agua (cf. Gemelli, 1996, p. 144, nota 10). Menciona este ejemplo en varias ocasiones: dos veces en las Cogitationes, donde lo introduce cuando presenta su primera adhesión al atomismo. En esa obra, la disolución del azafrán en agua es presentada como ejemplo de la sutilidad de la naturaleza, la cual sería un ejemplo a favor de la existencia de los átomos. La segunda vez, este ejemplo es usado para ilustrar analógicamente la distribución del vacío imperceptible en los cuerpos. Bacon escribe que las partículas de azafrán se distribuyen en un gran volumen de agua de la misma manera que los pequeños espacios vacíos se distribuyen en el interior de la materia de un cuerpo. Concluye que no hay

5 La interpretación de Rees respecto de que la sutilidad baconiana se reduce a la materia pneumática, no parece ser correcta, como así tampoco su inferencia de que Bacon rechazó el atomismo al haberlo reemplazado por el pneumatismo; cf. Rees (1980, p. 659). Véase la sección v de este artículo. 
razón para negar que la misma proporción entre vacío y materia pueda existir a nivel cósmico (cf. CNR, 3, p. 15, 17). ${ }^{6}$ Más tarde, en su Historia densi et rari (1623), discutirá este ejemplo en un contexto muy diferente. Explica que la dispersión del azafrán, como también otros instancias cortantes, es producida por una dilatación denominada per deacervationem (por difusión) (cf. HDR, 2, p. 285). En estas dilataciones, cuerpos cuyas partes están amontonadas pasan a ser achatados mediante un cambio en la posición de sus partículas (positura partium). Dado que no se produce un cambio de volumen sino de figura, Bacon las considera pseudo-dilataciones (cf. PHU, 3, p. ₹०7). Ciertamente, el proceso de contracción y dilatación, que constituye el eje central de Historia densi et rari, fue uno de los tópicos principales de la concepción atomista del mundo. La propuesta baconiana de explicar la sutilidad del azafrán como un caso de pseudo dilatación muestra su vínculo con la tradición atomista y su búsqueda de razones más satisfactorias que las aportadas por los filósofos que le precedieron.

Asimismo, Bacon intentó ofrecer una metodología científica que fuese lo más "sutil" posible, dado que creía que la "sutilidad" era un atributo intelectual imprescindible para que el filósofo natural alcance los objetivos de la ciencia. Señala que la sutilidad de la naturaleza supera ampliamente la sutilidad del entendimiento humano. Considera al lenguaje y el estilo literario de los escolásticos como un típico caso de sutilidad vana (cf. NO, 1, p.158, 160-1, 190, 215-6; VT, 3, p. 242). Con todo, Bacon está convencido de que si nuestro entendimiento es guiado por el método correcto, muchos de los secretos de la naturaleza se abrirán a la investigación científica (cf. SS, 2, p. 259; NO, 1, p. 234). Pero para que esto ocurra, la naturaleza debe ser en primer lugar separada en sus partes más sutiles a través de un procedimiento comparable con la disección atomística y la anatomía alquímica (mundi dissectione atque anatomia diligentissima). Es innegable la inspiración atomista que se asoma detrás de este programa y de hecho es confirmada por la entusiasta aceptación que Bacon hace del método de disección de Demócrito, al que puso en franca contraposición con el método aristotélico de abstracción (cf. NO, 1, p. 168-9; PO, 3, p. 83, 110; DIN, 3, p. 518).7 La filosofía de Demócrito es celebrada frecuentemente como el mejor acercamiento posible a la naturaleza, y es comparada con las filosofías antigua y contemporánea. En su teoría de los ídolos, por ejemplo, la generalización abstracta es contrapuesta a la investigación democritana sobre la naturaleza particular y concreta de las cosas.

6 Herón, que es mencionado por Bacon en este pasaje, ofreció un ejemplo similar: la dispersión de una pequeña cantidad de vino en el agua. Con el propósito de explicar este fenómeno, argumenta que las partes de vacío dentro del agua fueron ocupadas por el vino (cf. Heronis, 157 1, fol. B4).

7 Cuando Bacon caracteriza a Demócrito como un disector de la naturaleza, alude a un personaje pseudo-democritano descripto en una novela epistolar de los siglos iı y IıI (cf. Rütten, 1993, p. 55-63). 
En efecto, Bacon frecuentemente asocia el descubrimiento de la sutilidad de la naturaleza con la estrategia democritana de la disección (cf. Rees, 1980, p. 567-71). Esta disección del mundo físico, tan valiosa para Bacon, es por momentos vinculada con el examen de las formas, a las que presenta por primera vez en conexión con el método de Demócrito en el Novum organum (cf. NO, 1, p. 168-9).

En cuanto a la idea de anatomía de la naturaleza, Bacon se inscribe en una extensa tradición alquímica. La idea de "anatomía" de los alquimistas tiene un sentido más amplio que la mera disección de seres vivientes, tal como podría ser entendida en el campo de la medicina. No se la concibe sólo como una separación de las partes físicas de las sustancias químicas, sino también como un conocimiento teórico de las fuerzas invisibles que actúan como trasfondo. La idea fundamental de la anatomía alquímica se concentra en la distinción de las partes más generales que revelan las virtudes invisibles de la naturaleza. Oswald Croll, un discípulo de Paracelso, habla por ejemplo de una anatomia mundi, que se asemeja a la mundi dissectione atque anatomia diligentissima propuesta por Bacon (cf. NO, 1, p. 218, 277; Hannaway, 1975, p. 23-5; Pagel, 1982 [1958], p. 136-8; Eamon, 1994, p. 157-8). El método anatómico baconiano incluye no sólo la anatomía física, que permite distinguir los componentes más íntimos de los cuerpos orgánicos, sino acepta además la anatomía alquímica que se produce a través del fuego, el calor y los solventes, las destilaciones y las soluciones. Dedica especial atención a la anatomía corpuscular que, si está bien guiada, puede descubrir las partes homogéneas que constituyen los cuerpos macroscópicos. A pesar de sus posiciones a favor de la iatroquímica, Bacon no se cansa de alertar que la sutilidad de la naturaleza suele superar la mirada escrutadora del anatomista. Sin embargo, dado que el propósito de la ciencia es conocer no sólo los cuerpos visibles, sino también los corpúsculos invisibles, la anatomía iatroquímica debe complementarse con una anatomía inductiva (cf. DVM, 1996, p. 29v). La anatomía, ya sea ocular, mecánica o química, debe siempre estar guiada por una razón inductiva, que sea capaz de desarrollar una anatomía de carácter más general, comparativo y axiomático (cf. NO, 1, p. 234). El objetivo final y el límite de esta anatomía inductiva son las naturalezas simples, del mismo modo que para la anatomía médica y las destilaciones de laboratorio los cuerpos homogéneos son el punto final de la investigación. Bacon habla de la articulación de los distintos tipos de anatomía (iatroquímica e inductiva) en términos simbólicos: como "una transición que va de Vulcano a Minerva" (NO, 1, p. 234), es decir, comienza con la separación por medio del fuego y termina en la separación mediante la razón. Considera que los alquimistas han fracasado en la correcta utilización de Vulcano (fuego) por haber subestimado la utilidad de Minerva (razón), quien debió haber sido su guía y legítimo instrumento para separar los componentes de la naturaleza en la labor experimental (cf. ADV, 3, p. 325; DAU, 1, p. 489). 
Continuando con la discusión sobre la sutilidad de la naturaleza, Bacon distingue en Cogitationes dos significados de “átomo". Por un lado, el átomo puede ser entendido como el término último de la división de la materia. Esta primera definición implica que la materia está interiormente constituida y distribuida de una forma tan sutil que no llega a la percepción humana. Sin embargo, esta sutilidad no es infinita porque la materia no es divisible ad infinitum. La segunda definición de átomo presupone la existencia del vacío y describe al átomo como aquello que carece de vacío (cf. CNR, 3, p. 16-8; Lucrecio, 1947, 1, p. 510). ${ }^{8}$

De acuerdo con Bacon, el análisis que realiza Demócrito de los principios de la naturaleza es mejor que el tratamiento que le da al movimiento. Bacon trató de reconstruir la serie de argumentos que condujo a Demócrito a sus conclusiones acerca del movimiento atómico y supuso que el abderita debió haber comenzado por preguntarse sobre aquello que Bacon denominaba quaestio activa, a saber, "si todo puede hacerse a partir de todo" (CNR, 3, p. 18; 5, p. 422). Dado que una respuesta afirmativa parecía ser contraria a la razón, Bacon supuso entonces que Demócrito había concluido que todas las cosas provenían de átomos heterogéneos y que, como resultado, había formulado un modelo ontológico y especulativo para responder a esa quaestio activa. Al afirmar que los átomos eran diferentes en virtud de su figura, tamaño y posición, Demócrito tácitamente rechazaba la homeomeriae de Anaxágoras y establecía el principio ex nihilo nihil (cf. Gemelli, 1996, p. 147). A juicio de Bacon, la pregunta democritana ignoraba los datos empíricos, porque era incapaz de resolver (premere) la cuestión especulativa (quaestio speculativa) acerca de las propiedades de los átomos. Ya que si tenemos en mente las transformaciones intermedias que ocurren en los cuerpos, la verdadera pregunta debería haber sido "si todas las cosas cambian mediante transiciones intermedias y mediante círculos" (CNR, 3, p. 18; 5, p. 422). De acuerdo con Bacon, no es necesario postular que las partes últimas de la materia deben ser distintas entre sí, porque la variedad de los cuerpos proviene de la transformación gradual en las disposiciones de unidades materiales iguales (cf. CNR, 3, p. 18).

Tal vez influido por sus intereses alquímicos del momento, Bacon consideró a los átomos como equales et similares (siguiendo, según él, la perspectiva de Pitágoras). 9 En este sentido, se opone a la caracterización que atribuye a Demócrito, según la cual los átomos se diferencian por su figura, tamaño y posición. Parece haber pensado que la figura y el tamaño eran limitaciones a la posibilidad de transformación. Átomos desiguales dificultarían la continuidad material necesaria para obtener una propiedad

8 Urbach (1987, p. ₹3) se equivoca al señalar que Bacon aceptó en primera instancia esta definición para luego rechazarla. 9 Giordano Bruno vincula los átomos con los números y lo hace a la manera pitagórica (cf. Gemelli, 1996, p. 146-7). 
cualquiera a partir de un cuerpo que poseyera el conjunto de propiedades $x$. La doctrina de Demócrito consideraría a algunos átomos capaces de algunas transformaciones, mientras que otros átomos serían capaces de otras transformaciones. Por otro lado, si todos los átomos fuesen iguales, se abriría la posibilidad a transformaciones ilimitadas mediante simples cambios "numéricos" o geométricos. Un ejemplo de esto era la transformación (es decir, total alteración) de un pábilo en humo sin ningún residuo resultante (cf. GNR, 3, p. 18-9). Para sintetizar, entonces, en las Cogitationes, Bacon analiza y critica desde un punto de vista alquímico la explicación que Demócrito hace del movimiento. Demócrito es acusado de ignorar aquellos hechos naturales que manifiestan cambios intermedios, de basar su teoría del movimiento en proposiciones falsas, y de deducir de esas premisas la igualmente falsa doctrina que sostiene que los átomos son desiguales.

Bacon considera que los átomos son partículas mínimas que se combinan en distintas figuras y posiciones y operan en el vacío intersticial dentro de los particulares. Guando se lo entiende en ambos sentidos, el átomo se torna útil como un requisito para alcanzar los objetivos y cumplir las normas que rigen la nueva ciencia; dado que, en primer lugar, constituye la partícula última que subyace a todas las trasmutaciones de los cuerpos, y, en segundo lugar, en tanto es un cuerpo pleno (sin vacío), representa la persistencia del quantum material a través de los procesos de contracción por los cuales el vacío intersticial es expulsado de los cuerpos más grandes sin que por ello la materia sea aniquilada. Al mismo tiempo, Bacon incluye en su teoría un tipo muy especial de materia sutil y tenue denominada spiritus, la cual debería ser observada con cuidado y manipulada delicadamente por el filósofo natural. ${ }^{10} \mathrm{Si}$ bien Bacon no busca la causa última del movimiento atómico, sí investiga las condiciones requeridas para explicar los cambios: materia pneumática, átomos iguales y vacío intersticial.

A lo largo de este período, Bacon aceptó la descripción de los átomos que se asocia con Demócrito, es decir, la que sostiene que son duros y pueden coexistir en el vacío; luego cuestionó estos aspectos, pero nunca de manera consistente (cf. VT, 3, p. $\left.227^{-8}, 243\right)$. Desde un punto de vista metodológico, en un primer momento, Bacon pensó que la búsqueda de extremos en la naturaleza era un genuino propósito de la nueva ciencia y aceptó al átomo como una buena hipótesis para su teoría corpuscular de la materia (cf. TPM, 3, p. 537; Wolf, 1910-1913, 1, p. 274), porque servía como un principio ontológico y causal-operativo, que requería la existencia del vacío.

10 Más tarde, en HDR, Bacon diferencia diversas clases de materia pneumática; los spiritus son sólo una de ellas. En sentido estricto, spirit denota la materia pneumática que está encerrada dentro de cuerpos tangibles. 


\section{LA vis ATÓMICA Y LOS COMIENZOS DEL MUNDO}

De sapientia veterum (1609) señala el comienzo de una transición. En esta obra, Bacon se interesa profundamente en explicar la causalidad y el movimiento atómico. Ahora describe tanto a los átomos como a los espíritus como amos (domini) del movimiento. Explica una cantidad de fenómenos naturales combinando animismo con mecanicismo, y recurriendo a la mitología sin prestar atención a los datos experimentales. El breve relato del mito de Cupido, en De sapientia veterum, hace hincapié, por ejemplo, en el movimiento atómico. Cupido representa el movimiento natural del átomo. Se dice que el átomo es una antiquissima et unica vis, que se encuentra en todos los objetos creados a partir de la materia (ex materia). Bacon asume la existencia de vacío intersticial y concluye que la fuerza atómica opera sólo a distancia. Al mismo tiempo, la materia atómica primaria es descripta como dotada de stimulus, appetitus y simpatía (cf. DSV, 6, p. 655).

Bacon señala que los movimientos atómicos (ascendentes y descendentes) que fueron descriptos por Demócrito son insuficientes, dado que hay muchas otras clases de movimiento que no pueden ser reducidos a ellos (cf. DSV, 6, p. 655-6; PO, 3, p. 82; SS, 2, p. 34.6). " Aún sin definir el movimiento atómico primitivo, Bacon establece las condiciones de su existencia a través de la imagen de Cupido sagittarius. La acción a distancia es un caso eminente de las omnipresentes emanaciones encontradas en la naturaleza. Por lo tanto, según Bacon, si asumimos la existencia de átomos y de vacío, entonces la virtud atómica debe actuar necesariamente a distancia. Parece sostener que sin acción a distancia, todas las cosas permanecerían inmóviles en el vacío (cf. DSV, 6, p. 656). En la fábula de Pan, que está incluida en la misma obra, Bacon afirma que todas las cosas emanan virtudes inmateriales como si fuesen rayos (radii) (cf. DSV, 6, p. 637; DAU, 1, p. 525). Esta idea no es diferente de la vis radiativa de Walter Warner y Nicholas Hill. En la década de 1620, Warner estableció que la materia no podía moverse por sí misma sin un agente externo, por lo que postuló que la causa de su movimiento es una fuerza o virtud, también llamada vis radiativa. ${ }^{\mathbf{1 2}}$ Warner creía que la naturaleza de tal fuerza no es accesible al conocimiento humano. Puede causar sus efectos tanto por contacto directo como a través de un medio, a lo lar-go de transiciones graduales (cf. Kargon, 1966, p. 37; Jacquot, 1974, p. 117-9). Al igual que Bacon, Warner combina conceptos de corte neoplatónico y mecánico para explicar el fenómeno de la

11 Bacon confunde la concepción de Demócrito del movimiento con la del epicúreo Lucrecio. Acerca de las teorías del movimiento de Demócrito y Epicuro (cf. Wolf, 1910-1913, 1, p. 260-2; Pabst, 1994, p. 8-13, 45-9).

12 Warner apud Kargon, 1966, p. 37. 
percepción visual. El color no es nada más que la acción de una vis sobre los espíritus visuales que se refleja a partir de la estructura atómica del cuerpo. La percepción es definida en términos de estructuras atómicas y su causa es un movimiento de la energía radiativa (cf. Jacquot, 1974, p. 116-25; Kargon, 1966, p. 35-42; Henry, 1986). De la misma manera, valiéndose de Demócrito y Epicuro como autoridades, Bacon define las formas de los colores como la estructura corpuscular de cuerpos macroscópicos. Sin embargo, considera que la emisión de especies visibles es radial, incorpórea, a distancia y tenue, y describe las percepciones de los sentidos apelando a canales diminutos en el cuerpo humano (cf. VT, 3, p. 236-9; Rossi, 1990, p. 333-6). Nicholas Hill, cuya obra Philosophia epicurea, democritiana, theophrastica (1601) fue la única obra atomista en inglés que se publicó antes que de los escritos atomistas de Bacon, describe la vis radiativa en términos religiosos como un principio activo y causal divino. ${ }^{\mathbf{1 3}}$

De igual modo, las objeciones de Bacon a la doctrina epicúrea del movimiento atómico son de índole teológica antes que física (cf. DSV, 6, p. 655-6; MS, 7, p. 241). Encuentra que la teoría del clinamen y la explicación causal del movimiento son dignas sólo de burla (cf. TPM, 3, p. 537; DSV, 6, p. 656; DAU, 1, p. 571). ${ }^{\mathbf{1 4}}$ En un texto de índole religiosa, Meditationes sacrae (1597), distingue entre varios tipos de herejías. Acusa a Epicuro de trocar la noción democritana de "destino" por su noción de "fortuna". De ese modo, la filosofía epicúrea comete un error semejante al de aquellos herejes que no respetan el equilibrio entre el poder de Dios y el conocimiento divino. La perspectiva calvinista de Bacon está en contra de quienes piensan que, si bien Dios conoce los hechos que van a suceder, no los predetermina. En este sentido, la doctrina de la clinamen fortuita de los atómos presupone que Dios sabe más de lo que puede. En suma, lo que rechaza del epicureísmo es la ausencia de una rigurosa cadena causal no azarosa en la naturaleza, que sea reflejo de la presciencia de Dios (cf. MS, 7, p. 24.1; DAU, 1, p. 524). ${ }^{15}$

Al parecer, entonces, Bacon entiende la fortuna del azar atomista con la necesidad impuesta por la providencia divina. Mientras que Venus representa la disposición general y fatal hacia la procreación, Cupido encarna una simpatía específica dirigida hacia un individuo en particular. Con la acción de un mínimo de providencia, el átomo se mueve ciegamente hacia aquello por lo cual se siente atraído. Lo notable de este planteo es que Bacon considera que la providencia divina se revela admirablemente

13 Este concepto se encuentra también en los manuscritos de Harriot, aunque más esporádicamente que en Hill y Warner.

14. Sólo aquí Bacon adscribe a Demócrito la tesis del concursus fortuitus (cf. DAU, 1, p. 634; TPM, 6, p. 532).

15 Bacon repite en lo esencial las objeciones que los autores de la patrística usualmente le formulan al atomismo de Epicuro (cf. Gemelli, 1996, p. 20-4; Pabst, 1994, p. 30-44). 
cuando el azar interviene en los apetitos atómicos. Se maravilla ante la noción de que Dios se valga de una entidad ciega para obtener orden y belleza (cf. DSV, 6, p. 652). Más aún, justamente esa ceguera simboliza el hecho de que los movimientos atómicos están privados de finalidad (cf. Rossi, 1990 [1974], p. 195). Este concepto es similar al de la causa errante expuesta por Platón en el Timeo, 48a. En verdad, en este punto Bacon asimila la perspectiva platónica de la causalidad y la necesidad en el mundo físico (cf. Wolf, 1910-1913, 1, p. 124-5; DAU, 1, p. 550). ${ }^{16}$

Bacon se vale de otras figuras mitológicas, por ejemplo, de la figura de las Parcas, hermanas de Pan, para referirse a los destinos ( $f a t a)$ de las cosas individuales. Esta interpretación esbozada brevemente en De sapientia veterum, es considerada en mayor detalle en De dignitate et augmentis scientiarum de 1632 (cf. DAU, 1, p. 524; DSV, 6, p. 637), donde Bacon compara la cadena causal de las acciones de cada individuo con los hilos de las Parcas: ambos están ocultos y son difíciles de conocer (cf. DAU, 1, p. 524). Sin embargo, agrega Bacon, no existe nada en el orden de la naturaleza tan exiguo que no tenga una causa, ni nada tan grande que no dependa de otra cosa de acuerdo con certa lex.

La distinción entre destino individual y destino genérico conduce a Bacon a la cuestión epistemológica de la predicción, un tema que toca brevemente en la fábula de Proteo, donde afirma que una vez que el filósofo natural conozca la materia, será capaz de conocer las cosas presentes, pasadas y futuras. No obstante, su conocimiento estará limitado a los particulares (singularia) (cf. DSV, 6, p. 652). Esta afirmación no se reconcilia fácilmente con los supuestos mejor conocidos de su método inductivo. La historia natural debe empezar por los individuos ubicados en el espacio y en el tiempo, dado que cada especie tiene su propia uniformidad (cf. DGI, 3, p. 729). Bacon reconoce sólo dos genera individuorum como excepciones a esta uniformidad genérica: la primera, es la de los individuos que son únicos en su especie (como el Sol y la Luna entre las estrellas errantes); la segunda, es la de los individuos que están tan alejados de la naturaleza de su especie que es imposible clasificarlos como pertenecientes a ella (monstruos) (cf. DGI, 3, p. 729). En suma, la concepción básica de su historia natural asume que existe una similitud entre los individuos de la misma especie, de tal forma que si su forma respectiva es conocida, sus movimientos podrán ser predichos. En este aspecto, Bacon adopta un programa metodológico determinista moderado (cf. Hesse, 1983, p. 233).

En De principiis atque originibus, publicado alrededor de 1612, Bacon ofrece una detallada descripción ontológica de cómo el átomo habría operado en los comienzos 
del mundo. ${ }^{17}$ En ese momento, según nos cuenta, reinaba un estado de caos, y Cupido encarnaba a la materia prima cuya actividad estaba representada por la vis impuesta por Dios en la masa de las partículas primitivas. Concretamente, la materia prima no estaba despojada de forma, de apetito, ni de virtud - aunque éstas existían de manera muy simple e indeterminada - y aún carecía de la especificidad de los cuerpos complejos. Toda especificación subsecuente surgió como emanación de la materia prima, la forma prima y el principio del movimiento. Las propiedades tales como el peso, la dureza etc., así como también los diversos movimientos, provienen de las formas impuestas por la acción divina. Esta descripción que hace Bacon se reduce a una perspectiva puramente contemplativa, cuyo fin es separar con claridad los principios de los orígenes de las cosas, establecer la diferencia entre átomos y formas segundas, caos y cosmos. En este abordaje esencialmente histórico-ontológico sobre el átomo, Bacon no aborda en absoluto la cuestión de la relación del átomo con la práctica científica.

Bacon se vale de dos conceptos básicos - principio y origen - con el propósito de organizar más claramente en sus textos alegóricos su doctrina cosmológica. Estos dos conceptos deben tenerse en cuenta, si se quiere entender el atomismo alegórico y su relación con desarrollos posteriores en la teoría baconiana de la materia. La fábula de Cupido representa el principio del mundo, mientras que la fábula de Cielo habla de los orígenes del mundo. Dado que cada una representa una etapa distinta de la cronología del cosmos, los principia rerum (átomos de la materia prima) deben estudiarse antes que el origines mundi, que las formas del sistema del mundo (cf. PO, 3, p. 87).

Bacon introduce una innovación en la mitología del siglo xvi al identificar a Cupido con el átomo (cf. Lemmi, 1933). Al hacerlo, modifica sustancialmente la concepción vulgar de los comienzos del mundo, estableciendo un lazo primordial entre Caos y Cupido. La relación de la materia (Caos) con los átomos (Cupido) era en el origen un vínculo de total inclusión: la masa total de materia no era nada más que el agregado de partículas atómicas. Esta coexistencia de Caos y Cupido se pierde cuando la estructura fenoménica del mundo (también llamada schematismus magnus o systema mundi) es creada por Dios, y toda la materia preexistente alcanza su especificación máxima. De acuerdo con esta explicación, la creación implica un cambio de condición de la materia: a partir de un estado informe cambia para estar formada en su grado máximo. En lo que al Caos respecta, en tanto representación de la materia informe creada ex nihilo, en el momento en que se realiza la creación hexameral.

Esta transformación de la materia sin aniquilación es posible porque Cupido existía dentro de este Caos informis. En otras palabras, la masa de materia subsiste, e

17 La fecha de publicación de PO ha sido largamente discutida. Concuerdo con Graham Rees en considerar que el trabajo debe datar de una fecha no muy posterior a 1612 (cf. Bacon, 1996, 6, p. XXVIII-XXIX, nota 61). 
inclusive cambia, porque los átomos ya estaban contenidos en el Caos. El átomo es la entidad natural que persiste a través del cambio desde el Caos al cosmos y opera como un factor de continuidad. En el mundo divino, los átomos van del desorden al orden, produciendo estructuras atómicas ordenadas sin dejar de ser la forma prima y esencial de la materia. Aquí, Bacon no sólo apela a la mitología, sino también a las Sagradas Escrituras, glosando las primeras líneas del Génesis de la siguiente manera: "no está escrito que Dios creó la materia en el origen, sino que creó el Cielo y la Tierra" (cf. PO, p. K4, r, 3, p. 86). Esta materia pre-hexameral era informe sólo secundum totum (era un todo sin formas que ordenaran la materia en especies), ya que secundum partes, tenía una forma prima (el átomo es la forma prima que informa a la materia pre-hexameral en sus partes últimas). En este contexto bíblico, como en el anterior contexto mitológico, Bacon entiende por "creación” el comienzo en el tiempo del mundo ordenado, al que denomina en su propia terminología "origen".

En la fábula de Cielo, Bacon describe otras características de los orígenes del mundo. Desafortunadamente, De principiis no fue terminado, y carecemos de un conocimiento cabal acerca de lo que Bacon pensaba agregar en ese texto. La breve referencia al mito de Cielo en De principiis debería ser leída a la luz de la explicación ofrecida en De sapientia veterum, donde Bacon asocia a Cielo con el atomismo de Demócrito. El mito de Cielo habla de los diversos períodos de los orígenes del mundo que van desde el Caos hasta el presente. Cielo representa el espacio cóncavo que comprende a la materia. El mismo mito también hace mención del "tópico del infinito", ya que allí hay dos teorías del infinito a las que Bacon presta especial atención (cf. DSV, 6, p. 649, PO, p. Kııv, p. 94). La primera es la doctrina de Anaxágoras, que habla de un número infinito de principios formados y específicos (homeomeriae), a la que Bacon acusa de distorsionar la noción misma de "principio" ya que presupone que existe una diferenciación originaria en la naturaleza y de ese modo vuelve superflua la búsqueda del origen de la multiplicidad. Bacon considera que es obvio el hecho de que tal infinidad de homeomeriae no podría ser considerada como "principios" (cf. DAU, 1, p. 523, PO, 3, p. 87). La segunda teoría del infinito aludida es la que se asocia con el atomismo antiguo. Bacon se refiere a ella en Descriptio globi intellectualis (ca. 1612), escrita aproximadamente en la misma época que De principiis. En la Descriptio, que trata principalmente sobre astronomía, Bacon escribe que Demócrito había postulado la existencia de una cantidad infinita de materia pero una variedad limitada de formas atómicas (cf. TPM, 3, p. 537; ANN, 2, p. 86). ${ }^{18}$ A pesar de que algunos seguidores de Demócrito y Epicuro sostuvieron que sus maestros habían tirado abajo los muros del mundo, Bacon señala 
que sus premisas no implican ningún infinito. Los mundos multiformes que podrían haber sido conformados a partir de infinitos átomos podrían haber sido cerrados e incluso esféricos al igual que nuestro mundo visible. Además, si bien un universo infinito no podría poseer un centro absoluto, sí podría contener partes esféricas. En otras palabras, desde la óptica de Bacon, Demócrito analizó correctamente las partes del mundo pero no fue igualmente capaz para explicar su estructura general (integralibus mundi). Demócrito "fue un buen disector del mundo, pero en cuestiones vinculadas a su estructura fue aún peor que los filósofos comunes" (DGI, p. Eıv; 3, p. 737-8).

Si bien Bacon rechaza la noción de un mundo infinito, reconoce a su vez el gran valor de las explicaciones físicas de Demócrito de aquello que está "dentro del mundo". ${ }^{19}$ Un juicio relacionado con esta apreciación se expresa en la crítica baconiana de los peligros metodológicos que provienen del atomismo, formulada en los ídolos de la caverna. Allí comenta que mientras que algunas mentes tienden a prestar más atención al todo que a las partes, otras prefieren las partes. La investigación científica nos conducirá al error si le otorga importancia desigual a las partes y al todo. El error específico de la escuela atomista reside en su obsesión por las partículas y su casi total desinterés en considerar la estructura del mundo en sentido más amplio (cf. NO, 1, p. 170). Sin embargo, en la Descriptio, Bacon aún no cuestiona la validez ontológica de los átomos, como así tampoco su uso operativo. Lo que critica está vinculado con la cosmología y con la noción de un universo infinito, temas que ad parabolam Coelis pertinent (pertenecem a la parábola del Cielo).

\section{Los ATRIBUtos DEL ÁTOMo}

En las Cogitationes, los átomos dan cuenta de la extrema sutilidad de la naturaleza. En De principiis, Bacon continúa otorgándoles una serie de atributos para permitir que expresen esta sutilidad, al mantener que las entidades primeras no son cosas abstractas, como muchas teorías han erróneamente asumido, sino que siempre conllevan materia, forma y acción. Estas entidades primeras son precisamente los átomos, cuya existencia en la naturaleza debe estar más allá de toda duda (cf. PO, 3, p. 82-6). El átomo es una vis vel virtus, que es adornada (ornatus). Se trata, pues, de una forma prima de la cual proceden todos los demás atributos (cf. Briggs, 1989, p. 141). No obstante, estos átomos no se parecen a ningún cuerpo que podamos conocer perceptualmente:

19 Estoy en desacuerdo con Rees, quien ve aquí un rechazo de la astronomía y la noción de materia atómica de Demócrito (cf. Rees, 1980, p. 568). 
Por lo tanto, los átomos no son como chispas ardientes, gotas de agua, burbujas de aire, partículas de polvo, ni como pequeñas cantidades de espíritu o éter. $\mathrm{Su}$ poder y forma no es algo pesado o liviano, caliente o frío, denso o raro, duro o blando, tal como lo encontramos en los cuerpos más grandes, dado que esas virtudes y otras de la misma clase son compuestas y combinadas (PO, p. Iır, 3, p. 82$).{ }^{20}$

Con el fin de justificar la afirmación según la cual los átomos son los principios de las cosas, Bacon ofrece el siguiente argumento, en el que señala que el átomo es la materia prima, principio o causa de todas las cosas que poseen como su primera forma un apetito por la autoconservación:

\begin{abstract}
Ahora bien, un principio abstracto no es un ente y, por otra parte, un ente mortal no es un principio; de manera tal que una necesidad claramente irresistible conduce los pensamientos de los hombres (si buscan ser consistentes) al átomo, que es un ente verdadero dado que tiene materia, forma, dimensión, lugar, resistencia, apetito, movimiento y emanación. Asimismo, en medio de la destrucción de todos los cuerpos naturales, permanece constante y eterna. Ya que las corrupciones de los cuerpos más grandes son tantas y tan variadas, es absolutamente necesario que aquello que permanece como centro invariable deba ser algo o bien potencial o mínimo (PO, p. M3r, 3, p. 111).
\end{abstract}

Puede parecer sorprendente que Bacon quiera llevar este razonamiento a una conclusión por un recurso tal como la "necesidad irresistible" (necessitas invincibilis). No obstante, debe comprendérselo a la luz de su discusión acerca de los varios principios propuestos en la filosofía griega, los cuales asumen dos premisas fundamentales: "un principio abstracto no es un ente" y "un ente mortal no es un principio". Por consiguiente, un principio real no puede ser un ente abstracto. Sin embargo, la deducción de las otras propiedades atómicas (dimensión, lugar, resistencia o antitypia, apetito, movimiento y emanación) va más allá de esas premisas. El argumento tácito de Bacon

\footnotetext{
20 Según Rees (1980, p. 552, 563), lo que Bacon sostiene aquí es que los átomos "no son lo mismo que” (similes) los espíritus; por ende, Rees concluye que este pasaje señala una incompatibilidad entre los átomos y la materia pneumática. Y dado que la materia tangible puede convertirse en pneumática, deduce que la primera no está compuesta de partículas atómicas. Considero que Rees se equivoca porque confunde la relación que justamente se establece en PO, 3, p. 82. Con el propósito de argumentar a favor de la imperceptibilidad de los átomos, Bacon tiene que vérselas con una relación de similitud externa (similes), y no con una relación de identidad ontológica. Aunque hubiera señalado una relación de identidad, la conclusión de Rees no se seguiría, porque de “ $A$ no es idéntica a $B$ ” no necesariamente se sigue que $A$ es incompatible con $B$, ni que $B$ no está compuesta de $A$. En conclusión, PO, 3, p. 82 no trata sobre una incompatibilidad entre átomos y materia pneumática (cf. sección 5 de este artículo).
} 
debió haber sido de la siguiente manera: si la materia prima tiene alguna forma no específica, esta forma debe ser la más simple posible, es decir, su forma será la corporeidad, entendida como un quantum material extenso. Y para evitar que este quantum de materia sea destruido, necesita estar dotada de resistencia (antitypia), que lo protege contra cualquier agente que procure su aniquilación. La antitypia sirve a dos propósitos: la resistencia a la aniquilación y la conservación de la materia.

La noción de resistencia atómica se remonta a la tradición estoica, según la cual el término antitypia hace referencia a la resistencia de la materia, propiedad que marca la diferencia entre espacio y cuerpo (cf. Arnim, 1903-1924, 3, p. 315). Epicuro, a su vez, atribuye antitypia (es decir, la resistencia a la penetración) a la materia, en contraposición a la falta de resistencia propia del vacío (Epicuro, 1973, <24.49>29). En tiempos de Bacon, el concepto de antitypia reaparece en autores conocidos por él, tales como William Gilbert y Francesco Patrizi (cf. Gilbert, 1661, p. 66; Patrizi, 1583, p. 78r), quienes consideraban igualmente que la diferencia entre espacio y materia pasaba por la impenetrabilidad de esta última. Bacon adopta este concepto, pero a su criterio la antitypia es una propiedad esencialmente activa de la materia. ${ }^{21}$

La descripción de la antitypia ofrecida en el Novum organum (1620) señala que es uno de los movimientos primos, como previamente lo había descripto en De principiis, ya que Bacon la define como un movimiento inherente a cada porción de la materia, por medio del cual ésta puede luchar contra toda amenaza de aniquilación (cf. NO, 1, p. 33o, 4, p. 214). ${ }^{22}$ En este caso, la determinación del movimiento primo es la misma que la determinación de la forma prima. La antitypia atómica es la manifestación de la constancia en la cantidad de materia a nivel corpuscular, y esto constituye un principio fundamental de la física baconiana, en tanto Bacon, al igual que los averroístas, acepta la corporeidad indeterminada, pero además postula un movimiento de autoconservación. No es por mera casualidad que Bacon llega a esta afirmación, sino que se trata de la consecuencia de su visión cuantitativa de la naturaleza, que impregna tanto su filosofía especulativa como su filosofía práctica y atañe al reino de lo microscópico al igual que al de lo macroscópico en su filosofía natural. En el Novum organum, la antitypia es el único apetito material que no presupone la existencia de otra parte de materia, pero que a su vez es inherente a cada porción de la materia. Otros movimientos, por contraste, son relativos a otros cuerpos y por ende presuponen una multiplicidad de cuerpos (cf. NO, 1, p. 331-49). En otras palabras, la materia prima tiende a la autocon-

21 Tal como ha señalado Henry (1986), el concepto de materia como un ser esencialmente activo se vuelve un lugar común en el corpuscularismo inglés del siglo xvı. Bacon fue posiblemente uno de los primeros ingleses en introducir la actividad como una propiedad esencial de la materia, y lo hizo a través del concepto de antitypia.

22 Walter Warner también sostiene que la quididad de la materia consiste en la "corporeidad o resistencia (o antitypia o dureza)" (Warner apud Kargon, 1966, p. 36). 
servación sin necesitar de otra entidad para satisfacer este deseo. Respecto de los atributos dimensum et locatum, están justificados por y contenidos en la misma noción de antitypia. Dado que, si el átomo es resistente a la aniquilación, entonces debe poseer una dimensión espacial impenetrable.

En la filosofía natural de corte aristotélico, es una opinión común que la materia se conserva en virtud de la forma. En los comentarios conimbricenses a la Física de Aristóteles, la cuestión se plantea en la discusión acerca de la diferencia entre creación y conservación. Allí se sostiene que la distinción real entre la creación de la materia por parte de Dios y la conservación de la materia mediante la forma se debe a la distinción real entre materia y forma. En otros términos, la materia es conservada por la forma, que le es inherente desde el comienzo mismo de su existencia. Por su esencia puede ser conservada por Dios, pero en su existencia en el mundo físico es conservada por la forma. Así, la conservación constituye la primera ley del mundo físico qua físico (cf. Conimbricenses, 1616 [1592], libro 8, cap. 2, cuestión 1, articulo 4; Carvalho, 1999). Bacon coincide con los Conimbricenses en que la materia se conserva en la medida en que una forma reside en ella, contrariamente a lo que sostenían algunos agustinianos, quienes pensaban que la materia podía persistir sin forma alguna, al menos en caso de que Dios así lo quisiera (cf. Reif, 1969, p. 26).

En De principiis se ofrecen más elementos en torno al concepto baconiano del movimiento atómico y a su crítica a la teoría democritana. En este caso, se vale de la parábola de Cupido para demostrar la preservación de la "heterogeneidad" tanto en la sustancia como en el movimiento de los átomos. "Heterogéneo" se usa en un sentido particular, que trataré de explicar lo más claramente posible. Bacon sostiene que la explicación de Demócrito no es coherente porque él debió haberle atribuido a los átomos un movimiento heterogéneo (motum heterogeneum), tal como les atribuyó cuerpos (tamaños y figuras) y virtudes heterogéneos (cf. PO, 3, p. 82). Aún más, Demócrito les otorgó a los átomos más pesados un movimiento de descenso hacia el centro de la Tierra y a los átomos más livianos un movimiento de ascenso hacia los cielos, es decir dos movimientos "no heterogéneos" que pertenecen a dos tipos específicos de los cuerpos macroscópicos. Sin embargo, Bacon considera que el movimiento primo (motus primus) de los átomos debe ser "heterogéneo". Por lo tanto, hay una diferencia respecto de los movimientos específicos de los cuerpos más grandes (ascenso, descenso, contracción, rotación etc.), porque los comienzos de todo movimiento específico de los cuerpos macroscópicos deben estar contenidos en el movimiento primo de los átomos (cf. PO, 3, p. 82).

Otro atributo de los átomos es la inmutabilidad. Mientras que el átomo sufre cambios de posición, permanece idéntico en su sustancia. A pesar de que es en cierta medida difícil captar el argumento que Bacon propone aquí, puede reconstruirse a gran- 
des trazos como sigue. De acuerdo con la primera premisa, la inmutabilidad es consecuencia o bien de la potencialidad o bien de la minimalidad (esto es, la condición de ser el cuerpo lo más pequeño posible); pero la segunda premisa señala que no es posible adscribirle potencialidad al átomo, ya que en su calidad de primer ente potencial, no puede serlo en la misma forma en que lo son los demás entes potenciales. Por lo que "es necesario que sea completamente abstracto, ya que niega todo acto y contiene toda potencia” (PO, p. M3v, 3). Sin embargo, Bacon niega que un principio pueda ser abstracto, de lo que se sigue que el átomo no es potencial. Por consiguiente, la segunda alternativa debe ser la válida: la inmutabilidad atómica se debe al tamaño mínimo del átomo. Este atributo puede entenderse en un sentido cuantitativo al igual que en las Cogitationes, donde el átomo es definido como la minima portio de la materia, porque es indivisible (cf. CNR, 3, p. 15; Gemelli, 1996, p. 162; Lucrecio, 1947, 1, p. 609-27). ${ }^{\mathbf{2 3}}$

En cuanto a la emanación, es resultado de la triple caracterización del átomo como materia-forma-acción. Bacon se queja de aquellos filósofos que postularon que la acción (o el movimiento) era una emanación exclusiva de la forma separada de la materia. A su criterio, la emanación es una actividad difusiva de la vis atómica que trae como resultado la constitución de la multiplicidad del mundo tanto en sus movimientos (actiones, motus naturales) como en sus esencias y propiedades (essentiae, virtutes): "la materia (como quiera que sea) está de tal modo adornada, preparada y formada, que toda virtud, esencia, acción y movimiento natural puede ser la consecuencia y emanación de ella" (PO, K3v, 3, p. 86). ${ }^{24}$ La emanación parece constituir la clave con la que Bacon trata de explicar el pasaje de lo uno a lo múltiple, del caos al cosmos, de la potencia de los átomos para combinarse y constituir el mundo al acto de constitución del mundo real y concreto. Todo en la naturaleza, excepto el átomo, es a sus ojos un efecto de la emanación atómica, que es parte de la naturaleza dinámica de los átomos y se diferencia objetivamente de su apetito, movimiento y acción. La emanación describe un aspecto especial de la dinámica atómica, que es su poder para constituir la multiplicidad heterogénea del mundo. Bacon probablemente tomó prestado el término emanatio (un concepto acuñado por los neoplatónicos tempranos) de Telesio, quien lo revitalizó en el Renacimiento (cf. Telesio, 1586, 2, cap. 5-7, p. 50-2; PO, 3, p. 96-7). ${ }^{\mathbf{2} 5}$

23 Minimum tiene otros sentidos en DSV, 6, p. 656 .

24. "asserenda materia (qualiscunque ea sit) ita ornata et apparata, et formata, tu omnis virtus Essentia, actio, atquemotus naturalis ejus consecutio, et emanatio esse possit”.

25 Otra fuente pudo haber sido Roger Bacon, para quien era central el concepto de emanación. Francis Bacon menciona a Roger Bacon (cf. TPM, 3, p. 534), pero no tenemos evidencia de los manuscritos a los que haya podido tener acceso (cf. NO, 1, p. 89-9o). 


\section{MATERIA Y FORMA}

Ahora bien, ¿cómo explica Bacon que una única constitución atómica genere una multiplicidad cósmica de formas? La forma prima baconiana es menos específica que el resto de las formas y, por lo tanto, adquiere un status propio. A la luz de las ideas introducidas sobre todo en Novum organum y anticipadas en Valerius terminus (ca. 1603), es posible asumir que la emanación atómica produce formas de naturalezas simples, de cuya combinación surgen las naturalezas compuestas. En De principiis, Bacon niega que la densidad, la raridad etc. sean propiedades de los átomos, precisamente porque al ser más complejas, surgen de ellos. Si la emanación depende sólo del movimiento y de la forma de la resistencia, entonces, es necesario suponer que tal movimiento cambia, de manera que los movimientos complejos puedan surgir de él. No obstante, si tal cambio ocurre, no parece provenir del apetito de resistencia, que es meramente una búsqueda de autoconservación. En consecuencia, al parecer no hay alternativa mejor que postular una causa externa a la que Bacon identifica con la Palabra de Dios. Pero aquí parece surgir una paradoja que ha sido pasada por alto. Por un lado, se ha dicho que la materia prima es fundamentalmente activa y su apetito de resistencia a los movimientos es invencible. Sin embargo, por otro lado, su actividad es incapaz de superar la naturaleza inherentemente caótica de la materia, lo que lograría produciendo las especies por sí sola. Mientras que la vis de la materia prima es invencible y domina la naturaleza a principio usque ad finem, no alcanza a producir un cambio en su propio estado primitivo. En otras palabras, el átomo permanece ineficaz como principio de las cosas, si no cuenta con el auxilio de una nueva intervención de Dios.

Bacon es consciente de esta cuestión y se pregunta "si la materia creada, a través de largos períodos, hubiera podido por sí misma aglomerarse y convertirse en ese esquematismo perfecto, con la fuerza que le fue impuesta al comienzo" (PO, p. M2v, 3, p. 111). ${ }^{26}$ Esta pregunta había inquietado previamente a autores franciscanos tales como Petrus Olivus, quien sostenía que Dios había otorgado a la materia, al momento de la creación, la capacidad de moverse para adquirir determinadas formas. Según Olivus, la movilidad intrínseca de la materia es la manifestación de las razones seminales que son causas activas residentes en ella (cf. Pérez-Estévez, 1998, p. 331-2). Con todo, ni Bacon ni Olivus osaron concluir que la materia creada, sin la mediación divina y por sí sola, hubiera podido llegar a constituir el sistema del mundo. Bacon se limita a sugerir que quizás la cuestión no deba ser preguntada, pero no nos explica el por qué de esta

26 "Utrum vero Materia illa creata, per longos saeculorum circuitus, ex vi prima indita, se in illum optimum Schematismus colligere et vertere potuisset...”. 
prohibición. Briggs (cf. 1989, p. 141-2) sostiene que la causa del silencio de Bacon sería su temor de dar una respuesta no ortodoxa que podría ocasionarle una censura por parte de autoridades religiosas. Tal vez esta sea sólo una de las razones del silencio de Bacon. Es posible que exista otro motivo: aparentemente, Bacon tenía dudas respecto del poder causal de los átomos. En consecuencia, no sostuvo una posición definitiva. De hecho, en De principiis, parece haberle atribuido más poder a los átomos que en obras anteriores. En A confession of faith (1602), dice que las leyes de la naturaleza "comenzaron a entrar en vigencia" una vez terminada la obra hexameral (cf. CF, 7, p. 221). Posteriormente, en De sapientia veterum delimita claramente el comienzo de la intervención de la fuerza atómica en el mundo una vez que las especies hubieran sido creadas por Dios. Para ese entonces, Bacon sostenía que Cupido era el más joven de los dioses "ya que no podría haber actuado antes de que hubieran sido constituidas las especies" (DSV, 6, p. 656). ${ }^{27}$ Por último, en De principiis, Bacon aparentemente comienza a dudar acerca de si la actividad de la materia podría haber vuelto superflua la intervención divina en la creación de las especies, pero cautelosamente parece preferir ocultar esas dudas.

Mientras que en De principiis Bacon habla de forma prima y ubica su capacidad para emanar al mismo nivel que la materia prima, en Novum organum habla de formas segundas (subdivididas en formas de naturalezas simples y compuestas) y les atribuye un poder de emanación especial. Estas formas son caracterizadas como fons emanationis, natura naturans, mientras que los cuerpos son denominados natura naturata. En el siglo xvir, la fusión del neoplatonismo y el aristotelismo creó la noción de forma como agente emanativo, cuyos efectos se encuentran tanto en los movimientos espontáneos de los elementos como en la producción de los accidentes propiamente dichos (cf. Reif, 1969, p. 27; Pérez-Ramos, 1988, p. 90-1). En contraste con este contexto, en Novum organum la agencia emanativa de la forma es concebida fundamentalmente como la consecuencia de su carácter esencialmente operativo. Cuando Bacon introduce allí su propio concepto de forma e intenta alejarlo de las formas sustanciales de los aristotélicos, la aplicabilidad científica parece constituir su principal criterio para hacerlo. La forma baconiana no es sólo una ley teórica sino además una norma operativa que le permite a la ciencia manipular la naturaleza exitosamente. De esta manera, la forma posee una capacidad de "emanar" actos artificiales que la materia no tiene (cf. PérezRamos, 1996, p. 115-22).

El tratamiento que Bacon hace de Cupido en De principiis distingue entre esencia y sistema y ejemplifica esta distinción en las dos entidades primarias: materia y forma. 
Bacon considera a los dos como leyes, aunque de distinta incumbencia. La materia prima es la unica et summaria lex de la naturaleza y está en el vértice de la pirámide del conocimiento, representando el elemento de unidad en la naturaleza del que emerge toda la variedad del mundo natural mediante su propia multiplicación (cf. DAU, 1 , p. $5_{67}$, 655; VT, 3, p. 220; PO, 3, p. 81, 86). Las formas, a su vez, surgen de la agregación de átomos que se diferencian entre sí por su posición y cantidad (cf. NO, 1, p. 168-9, 228, 232, 262).$^{\mathbf{2}}$ En De principiis, Bacon recuerda lo que ya había dicho en Novum organum: "una Forma verdadera es tal que deduce una naturaleza dada de una fuente de esencias que está presente en muchas cosas y que, como dicen, es más conocida para la naturaleza que la forma misma" (NO, 1, p. 23o). ${ }^{29}$ En términos lógicos, la fons essentiae es el género de la naturaleza dada (instar generis veri). Así, por ejemplo, el movimiento es el género de la forma "calor" (cf. Pérez-Estévez, 1998, p. 120-5). En términos físicos, la denominación de la materia como "fuente de esencia" parece describir una naturaleza de carácter más general que cualquier sustancia física dada. Si se tomara en cuenta la jerarquía de la física, podría constituir la esencia primerísima, sería la ley suma de las esencias que reside en la materia prima.

En la naturaleza, siempre hay movimiento y toda forma es, en última instancia, reducible al apetito de la materia por su conservación (cf. Jardine, 1974, p. 109-12; Fattori, 1983). La reductibilidad de cualquier forma a la forma prima de la resistencia es de suma importancia ya que manifiesta una vez más que en la filosofía natural de Bacon el movimiento es una determinación primera y universal de la materia. No hay realidad natural sin movimiento, es por eso que la nueva filosofía debe indagar los principia moventia rerum. Forzada a persistir a través de los cambios, la materia debe siempre seguir moviéndose para conservar su identidad. La pasividad le es, entonces, ajena. Como consecuencia, Bacon se ve obligado a rechazar la perspectiva de Telesio que sostenía que el calor y el frío son los principios que mueven la materia, que es esencialmente pasiva.

El quadro 1 ofrece un esquema de los diversos temas que he analizado hasta el momento. Están agrupados de acuerdo a la bipolaridad de principio y origen. Es obvio que De principiis, por el hecho de ser una obra inconclusa y póstuma, impone severos límites a las posibilidades de interpretación. Sin embargo, la consideramos de sumo valor para la interpretación, no sólo en sí misma, como expresión de una etapa del

28 Lemmi (1933, p. 94) y Hesse (1983, p. 229, 238) han notado que la forma baconiana debe entenderse como un agregado atómico. Gemelli (1996, p. 312-3) sostiene que la primitiva inseparabilidad y coexistencia del atomismo y las formas ya está presente en GNR.

29 "Forma vera talis est, ut naturam datam ex fonte aliquo essentiae deducat quae inest pluribus, et notior est naturae (ut loquuntur) quam ipsa Forma". 
pensamiento atomista de Bacon, sino en relación con la totalidad del corpus baconiano especialmente respecto a Novum organum. De hecho, es posible leer los principales conceptos de su filosofía natural y los aforismos introductorios clave del segundo libro del Novum organum desde esta perspectiva. Además, ayuda a entender por qué Bacon puso en cuestionamiento el modelo atómico en su última gran obra.

\begin{tabular}{|c|c|c|}
\hline & Unidad de la naturaleza & Multiplicidad de la naturaleza \\
\hline Concepto organizador & Principio & Origen \\
\hline \multirow[t]{2}{*}{ Estado } & Caos & Pan \\
\hline & Materia desordenada & Sistema del mundo \\
\hline Agente sobrenatural & Creación ex nihilo & Obra de los seis días \\
\hline & obra de manufactura & obra de estilo \\
\hline & (materia) & (actos-leyes) \\
\hline Figuras alegóricas & Mercurio & Penélope y sus pretendientes ${ }^{3 \circ}$ \\
\hline Agente natural & átomo/materia prima: & formas: \\
\hline & ley suma de las esencias & leyes de actos \\
\hline & fons essentiae & fons emanationis \\
\hline Figuras alegóricas & Cupido & Cielo, Saturno, Júpiter etc. ${ }^{31}$ \\
\hline Formas intervinientes & $\begin{array}{l}\text { Forma prima: } \\
\text { antitypia }\end{array}$ & $\begin{array}{l}\text { Formas segundas } \\
\text { (simples y compuestas) } \\
\text { cualidades/especies/géneros }\end{array}$ \\
\hline
\end{tabular}

La diferencia entre principio de las cosas y origen del mundo, tal como ha sido esquematizada en el cuadro precedente, es también útil para analizar la perspectiva baconiana de la relación entre la materia y la forma. A primera vista, Bacon parece sostener puntos de vista incompatibles. En su interpretación del mito de Pan, que se describe en De dignitate, encontramos que sorprendentemente manifiesta su acuerdo con el concepto de materia "desnuda" de Platón y Aristóteles. Luego de examinar diversas teorías sobre el origen del mundo, Bacon dice:

3o Penélope representa la materia penetrada por las formas (simbolizadas por los pretendientes).

31 Cada deidad representa un aspecto diferente del proceso que desemboca en el mundo actual, el que, de acuerdo a las Escrituras, es producto de la obra hexameral de Dios. 
Pero quienes introdujeron una materia absolutamente despojada, informe e indiferente a las formas (como Platón y Aristóteles) accedieron de manera mucho más acertada y cercana a la figura de la parábola [de Pan]. Pues pensaron la materia como una meretriz pública y las formas como sus pretendientes (DAU, 1, p. 523,4, p. 320$){ }^{32}$

Este pasaje es difícil de interpretar, habida cuenta que en de De principiis Bacon afirma que la materia prima no es abstracta ni desnuda y considera mayormente falsas las cosmologías platónica y aristotélica, justamente porque asumían un concepto de materia abstracta (cf. PO, 3, p. 84). Por el contrario, los filósofos presocráticos se habían acercado en diversos grados a la verdad. Algunos le habían atribuido mutabilidad al principio de la naturaleza (Tales, Anaxímenes, Heráclito); otros habían sostenido que existen muchos principios (Empédocles, Parménides y, mucho después, Telesio). La perspectiva de Demócrito es la que más cerca llegó a la naturaleza de las cosas, dado que postuló un principio único e inmutable.

En De principiis y De dignitate se encontran dos fragmentos muy similares que parecen afirmar, no obstante, el punto de vista opuesto. Con el fin de entender lo que Bacon quiere decir en cada uno de ellos, deben tenerse en cuenta los distintos contextos en los que se insertan. El primero describe el momento inicial de la historia de la naturaleza, el Caos. El segundo se concentra en la etapa post-hexameral, bajo el primado de Pan. En consecuencia, se está describiendo un sentido diferente de "forma" en cada una de las situaciones. Cuando se dice que la materia es "formada" ex parte, "forma" significa la primera determinación de la materia, es decir, su resistencia a la aniquilación. Cuando se dice que la materia es "informe" ex toto, "forma" se refiere a la ley por la cual los cuerpos actúan, o su causa formal. A esta distinción apunta la interpretación baconiana de la vestimenta de Cupido.

Cupido desnudo - tiene una identidad per se, pero desnuda - se ve reflejado en el átomo, un principio que es simple y es una sustancia única. De acuerdo con Bacon, otras teorías se equivocaron y atribuyeron excesiva determinación a la materia prima al considerarla compuesta por las formas segundas, como si Cupido estuviese vestido (non exuto). Tales teorías sobredeterminaron la materia prima y se equivocaron mucho más que aquellos que sostuvieron que la materia era absolutamente abstracta (cf. PO, 3, p. 86-7). En síntesis, comprender las polaridades conceptuales de Bacon, tal como han sido esquematizadas más arriba, nos ayuda a encontrar continuidad temática a lo largo de los diferentes fragmentos y obras.

32. "Qui vero Materiam omnio spoliatam, et informem, et ad Formas indifferentem introduxerunt (ut Plato et Aristoteles) multo etiam proprius et propensius ad parabolae figuram accesserunt. Posuerunt enim Materiam tanquam meretricem, Formas vero tanquam procos." 
Cuando Bacon explica en De dignitate los orígenes del mundo mediante la fábula de Pan, muestra cierta afinidad con la noción de materia informe. Allí discute la cuestión de si la formación del mundo a través de sucesivos períodos es el trabajo de un Dios único que creó el caos material. En el momento histórico del caos, la "materia del Cielo y la Tierra fue creada sin las formas" (CF, 7, p. 221). En otras palabras, el acuerdo con Platón y Aristóteles se limita al período de la historia de la naturaleza en el que la materia estaba absolutamente desnuda, informe y privada de formas secundarias.

Por el contrario, el tema de De principiis es el átomo y su relación con Caos, tal como queda aclarado cuando se tiene en cuenta el papel que juega la fábula de Cupido. Allí, quiere enfatizar el contraste entre el caos pasivo e informe y la materia prima activa y formada, respecto de los que dice que coexistían antes de que comenzara la creación hexameral. Para Bacon, tanto la materia prima como la masa caótica primigenia son entidades materiales cuya única marca individualizante es que las partes pueden ser distinguidas del todo. Desarrolla luego un análisis minucioso de la materia prima como el contexto a partir del cual pueden criticarse las diversas cosmologías griegas. Notablemente, Bacon evalúa si los platónicos y los aristotélicos le conceden atributos a la materia prima que fuesen adecuados con los que le atribuye en De principiis. El resultado de esta evaluación es que esa descripción de la materia prima como abstracta, potentialis, informis, spoliata, passiva, fluens, tanquam accessorium formae, phantastica es inaceptable, pues no cumple con el criterio que él propone. A propósito, su análisis delata una vez más una deuda tanto con la explicación agustiniana de la creación (con su dualidad conceptual de creare et facere) como con la concepción franciscanaaverroísta de la materia prima. En suma, los respectivos rechazo y aceptación de las concepciones platónica y aristotélica de la materia informe dejan de ser contradictorios una vez que se tienen en cuenta los contextos en los que se insertan.

Bacon también se ocupa de este tema en otro lugar. Rechaza con vehemencia la distinción aristotélica entre mundo supralunar y mundo sublunar, y señala que la materia sublunar aristotélica parece una prostituta que desea las formas, mientras que compara la materia supralunar con una madre; caracterizaciones que se acercan más a la superstición y la opinión popular que a la filosofía seria (cf. GNR, 3, p. 33). En esta crítica, rechaza nuevamente la distinción entre dos mundos y, por ende, entre dos tipos de materia. Es de notar que esta objeción no implica que Bacon se oponga al hecho de admitir la existencia de materia informe anhelando formas, sino sólo a la identificación de esa materia con la materia del mundo sublunar.

Una explicación similar puede encontrarse en Sylva sylvarum, donde Bacon reporta evidencias experimentales de cuerpos "insatisfechos" que desean absorber otros cuerpos. Por ejemplo, el aire recibe luz, sonidos, olores y vapores. La causa de estos fenómenos no es explicada, pero Bacon escribe: "en cuanto a la bonita afirmación de 
que la materia es como una prostituta vulgar que desea todas las formas, sólo es una noción vaga" (SS, 2, p. 6o1). Una noción, en otras palabras, sin fundamentos sólidos.

En líneas generales, Bacon parece considerar los conceptos de principio y origen como independientes uno del otro. Esto quiere decir que debe haber pensado que era posible que una teoría pudiera especular de manera correcta acerca del sistema del mundo, aunque al mismo tiempo postulara principios erróneos. De acuerdo con $\mathrm{Ba}-$ con, la filosofía de Telesio representa un caso semejante. Telesio hablaba non male acerca del sistema del mundo, pero imperitissime sobre sus principios (cf. PO, 3, p. 110). Por el contrario, la explicación acerca del sistema del mundo que ofrecían los presocráticos había sido muy exitosa, aunque hubieran errado al tratar de establecer en qué consiste el principio.

Puede parecer sorprendente que luego de haber buscado e identificado el principio atómico de la naturaleza, implícitamente Bacon admita que una confusión acerca del principium resulta irrelevante para el desarrollo de teorías sobre los principiata. A pesar de que evalúa positivamente las especulaciones de Telesio acerca de las especies naturales, también las ve limitadas porque no pueden dar cuenta de los esquematismos materiales (cf. PO, 3, p. 79, 87, 111, 114). Sin embargo, ¿significa esto que se puede especular adecuadamente sobre el fenómeno del calor, como en el caso de Telesio y, al mismo tiempo, ignorar que el calor es un tipo de movimiento corpuscular? (cf. NO, 1, p. 266) ¿En qué sentido puede decirse que una filosofía especula non male, si no explica las formas en términos de estructuras atómicas? De manera indirecta, estas preguntas tienen que ver con la relación entre conocimiento y poder en el marco del programa baconiano. Pues, ¿cuál es la importancia de conocer que el calor es causado por el movimiento atómico, si es posible manipularlo a pesar de contar con un conocimiento tan incompleto? La observación de Viano respecto de que el eje del programa baconiano del conocimiento está heurísticamente orientado hacia la praxis científica parece ser correcta (cf. Viano, 1954). No revela la relación ideal, sino la relación verdadera entre el conocimiento y el poder en el ámbito de la ciencia. En consecuencia, es comprensible que Bacon haya aprobado ciertas tesis telesianas que le sirven como instrumento para alcanzar determinados efectos operativos, más allá del hecho de que ignoraran la constitución misma de la materia.

\section{Esquematismos LATENTES Y MATERIA FLEXIBLE}

En Novum organum (1620), se da un punto de inflexión donde, al igual que en Cogitationes, se considera a la teoría atomística como un instrumento para alcanzar los objetivos operativos de la ciencia, sin que eso implique la toma de decisiones vinculadas 
con la verdad o la falsedad. Los requisitos del método inductivo conducen a Bacon a introducir conceptos causales más precisos, que puedan brindar una explicación de la evidencia experimental. Tal como lo hace en Cogitationes, Bacon habla de la teoría atomista como un elemento útil para lograr los propósitos de la nueva ciencia, pero no se expide sobre su valor de verdad. En el marco de su exposición acerca de los ídolos del teatro, hace una observación metodológica respecto de que todas las explicaciones últimas son útiles para la praxis científica, "dado que toda utilidad y oportunidad para la aplicación reside en las causas medias" (NO, 1, p. 178), ${ }^{33}$ Bacon pone de relieve esta cuestión tanto contra la extrema abstracción de los aristotélicos como contra la extrema disección de los atomistas. En Novum organum, no se ocupa de la materia potencial aristotélica ni del atomismo antiguo, sino de la capacidad de determinadas entidades para desempeñar roles funcionales en una ciencia de corte inductivo, roles que no puede jugar la materia potencial e informe de los aristotélicos como así tampoco los átomos de Demócrito y Epicuro. Incluso en el caso de que "fuesen verdaderos, podrían contribuir poco a mejorar el destino de los hombres" (NO, 1, p. 178). ${ }^{\mathbf{3}_{4}}$ Desde este punto de vista, el átomo, un ente de extrema sutilidad, resulta de poca utilidad para la ciencia baconiana.

Inclusive, Bacon continúa persuadido de que la investigación de la naturaleza debe realizarse a través de una separación anatómica de sus partes más íntimas. No obstante, aclara que el concepto de átomo, que presupone una materia inflexible y el vacío, no debe ser la unidad de análisis que guíe tal investigación anatómica. "Pero no debemos entonces terminar en el átomo, que presupone un vacío y una materia rígida (dado que ambos presupuestos son falsos), sino con las verdaderas partículas (particulas veras) tal como se encuentran" (NO, 1, p. 234)..$^{35}$

Estas partículas verdaderas no son otra cosa que las primeras configuraciones de la materia a las que Bacon denomina schematismi latentes. ${ }^{36}$ Aunque son imperceptibles a simple vista, representan la verdadera textura de las cosas, que determina sus virtudes específicas. Bacon no es muy claro al explicar el significado de estos esquematismos materiales latentes. Al parecer se trata de conglomerados de partículas, de cuya composición se deriva la múltiple heterogeneidad de los cuerpos. Solía asumirse que los átomos clásicos de Leucipo y Demócrito estaban conformados por materia dura

33 "omnis utilitas et facultas operandi in mediis consistat".

34 "quae, etiamsi vera essent, tamen ad juvandas hominum fortunas parum possunt."

$3_{5}$ "Neque propterea res deducetur ad Atomum, qui praesupponit Vacuum et materiam non fluxam (quorum utrumque falsum est), sed ad particulas veras, quales inveniuntur."

36 Rees (1984, p. 223-43), distingue tres significados de schematismus en Bacon: la estructura total del mundo (schematismus magnus), el nombre genérico de toda cualidad simple (schematismus materiae), y las configuraciones microscópicas (schematismus latens). En el presente trabajo usaré “esquematismo" en este último sentido. Gemelli (1996, p. 182-95) explica algunas de las características del esquematismo baconiano y su deuda con el de Lucrecio. 
e inflexible (materia non fluxa). Sin embargo, a criterio de Bacon, si la materia tiene tal rigidez, será imposible que ocurrieran las trasmutaciones intermedias que de hecho tienen lugar cuando los cuerpos cambian sus propiedades. La trasmutación de los cuerpos - a propósito, el objetivo principal de la práctica científica - debe ocurrir a partir de cambios en los esquematismos, no en los átomos. Respecto del vacío, que era el otro pilar del atomismo antiguo, Bacon no lo considera necesario para explicar los cambios de volumen. Por el contrario, apela a los pliegues de la materia (plicae materiae), que le permiten a la materia cambiar su volumen sin necesidad de que exista un vacío intersticial (cf. NO, 1, p. 347).

Es importante notar que, a pesar de esta revaluación del atomismo que Bacon realiza en Novum organum, el vocabulario corpuscular permanece intacto en obras tardías tales como De dignitate et augmentis scientiarum, Historia densi et rari, Sylva sylvarum etc. De hecho, expresiones tales como cuerpos diminutos (res minutae, particulae minutae y minima) son usadas frecuentemente en estas obras para describir la realidad física, lo que pone de manifiesto que el corpuscularismo sigue operando como una de las bases teóricas de la física baconiana (cf. CNR, 3, p. 31; NO, 1, p. 265, 3o7; PO, 3, p. 82; SS, 2, p. 381). ${ }^{3}$ A la luz de ésto, se comprende por qué los conceptos atomistas expresamente asociados con Demócrito aún conservan su lugar entre los primeros axiomas de la filosofía. Por ejemplo, leemos: "la naturaleza de todas las cosas se manifiesta mejor en sus porciones más pequeñas” (DAU, 1, p. 541, 4, p. 338). 38 Aún más, la idea de que cada movimiento tiene su causa última a nivel microscópico se mantiene como un principio indudable. Así, cada acción natural se lleva a cabo per minima o al menos mediante unidades demasiado pequeñas como para ser percibidas por los sentidos. Los metaesquematismos más sutiles no son otra cosa que lationes per minima (traslaciones a través de lo mínimo) (cf. NO, 1, p. 232-3). Pero no sólo los movimientos, sino también la materia aparece como minima, y este fenómeno es explicado en términos tanto de minutae lationes como de minutae particulae. Por ejemplo, el calor es definido como el movimiento de las minutae particulae, aunque estas partículas diminutas involucradas no sean extremadamente sutiles (cf. NO, 1, p. 265). Se sostiene también que las partículas mínimas explican el origen de algunos sonidos (cf. SS, 2, p. 343, 391). De igual modo, procesos biológicos como la asimilación de los alimentos y los cambios en la temperatura sanguínea suceden per minima (cf. HVM, 2, p. 182, 197). Teniendo en cuenta la crítica del atomismo anunciada en Novum organum, no se deben confundir estas minima con la minima portio de las Cogitationes y De principiis. Aunque Bacon no es muy riguroso en el uso del vocabulario, parece claro que usa minutae, mi-

$3_{7}$ Inmediatamente después, "diminuto" será usado como un atributo general de los átomos, por ejemplo, por Henry Power (cf. Gemelli, 1996, p. 150-4, 170).

38 "Naturam se potissimum prodit in minimis". 
nima etc. como términos equivalentes para denotar pequeñas porciones de materia, sin referirse ya a aquellas porciones absolutamente ínfimas e indivisibles de las que había hablado en sus obras anteriores.

Sylva sylvarum contiene un fragmento que expresa los niveles de realidad material que Bacon llega a distinguir en sus últimos escritos. En este pasaje, se queja de que la investigación de la naturaleza habitualmente ha estado limitada a las cosas visibles, mientras que "aquello que es invisible, tanto respecto de la fineza del cuerpo mismo como de la pequeñez de las partes, o la sutilidad del movimiento" es desestimado casi por completo. Hay cuatro tipos de entidades que pertenecen a esta clase de seres invisibles no investigados:

(1) los espíritus; (2) las partes tangibles; (3) las partículas mínimas y sus posturas ("las diferencias más sutiles de las partes mínimas y su postura en el cuerpo"); (4) los movimientos de las partículas y los movimientos internos de los cuerpos que se dan entre espíritus y partes tangibles.

Es de destacar que el átomo no se incluye en esta lista de objetos invisibles que son científicamente relevantes. La crítica de Bacon continúa:

Respecto de las diferencias más sutiles de las partes mínimas y su postura en el cuerpo (...) no son tenidas en cuenta. En cuanto a los movimientos de las partes mínimas de los cuerpos, que tienen efectos tan importantes, no han sido observados en absoluto, porque son invisibles; pero pueden ser descubiertos por la experiencia (...) Demócrito estuvo en lo cierto cuando se defendió de la acusación de sostener que el mundo estaba hecho de partículas tan pequeñas como las que se ven al sol: "Nunca nadie vio un átomo, pero a partir de la razón y por la experiencia hay convencimiento de su existencia" (SS, 2, p. 384).

Pace Rees (cf. 1980, p. 564), esta referencia a Demócrito parece algo más que una mera invocación a la autoridad presocrática. En verdad, Bacon parece remitirse a Demócrito para plantear una cuestión epistemológica. La cita también parece aceptar la noción atomista de sutilidad de la naturaleza. Si Bacon hubiera rechazado por completo la teoría atomista, como interpreta Rees, entonces ¿por qué no declaró expresamente su oposición al atomismo en este importante pasaje, que es uno de los pocos en Sylva sylvarum donde trata sobre cuestiones teóricas acerca de la constitución de la materia? Bacon suele expresar sus diferencias con otros filósofos con el fin de distanciarse de ellos, pero obviamente, este no es el caso de la afirmación democritana que señala que los corpúsculos últimos son imperceptibles. 
La interpretación que aquí sostengo pone también en cuestión la lectura de Kargon, quien sostiene que Bacon suscribió en un principio a una terminología atomista para luego cambiarla por el lenguaje pneumático de la alquimia. Kargon considera que este cambio en la terminología apunta al alejamiento de una teoría mecanicista y atomista, para suplantarla por otra de corte animista y pneumático (cf. Kargon, 1966, p. 42). Sin embargo, creo que es imposible encontrar ese modelo mecanicista atomista incluso en los escritos más tempranos de Bacon. Kargon se equivoca al pensar que el atomismo de Bacon estuvo en algún momento cerca de la ortodoxia democritana (cf. Hesse, 1983; Gemelli, 1996). De hecho, difícilmente es posible encontrar explicaciones mecanicistas puras en su obra. Es verdad que los enfoques mecanicistas y animistas se combinaron en escritos tardíos tales como De sapientia veterum, donde el movimiento animista a distancia se explica en términos de simpatías materiales. Incluso en los textos más tempranos, los vocabularios atomista y pneumático aparecen conectados. Los procesos de alteración y separación, el vuelo de los espíritus y los apetitos de Cupido coexisten con nociones de corte más mecanicista como el vacío y las partículas mínimas. Por otra parte, Bacon siempre marcó claramente la diferencia entre los átomos y la materia pneumática y distinguió con cuidado los átomos del pneuma, del mismo modo que diferenció los átomos de toda otra manifestación material (cf. PO, 3, p. 82). Además, sus obras alegóricas tempranas parecen sugerir que la materia pneumática está compuesta por átomos.

Rees refuta las afirmaciones de Kargon acerca del supuesto cambio desde el atomismo hacia el pneumatismo realizado por Bacon, señalando que Bacon nunca ofreció explicaciones completamente mecanicistas, aunque pueden encontrarse rasgos de ese tipo de pensamiento a lo largo de su obra (cf. Rees, 1980, p. 563- ). Si bien, por un lado, acuerdo completamente con esta lectura de Rees, por otro lado, no comparto su conclusión según la cual, a partir de ello, es manifiesto que Bacon nunca se comprometió con el atomismo. El hecho de que Bacon modifique el atomismo griego y no considere favorablemente las explicaciones mecanicistas no significa que en Cogitationes, De principiis y De sapientia veterum no haya asumido concepciones atomistas. ${ }^{39}$

Rees parece sobreestimar el papel asignado a la materia pneumática. Si tal como este autor concede, Bacon postuló simultáneamente la existencia de materia tangible y de materia pneumática, ofreciendo también explicaciones mecanicistas y no mecanicistas al mismo tiempo, ¿qué razones hay para describir su teoría de la materia como exclusivamente "pneumática"? (cf. Rees, 1980, p. 563). Ni siquiera considero que pueda sostenerse que Bacon privilegia la materia pneumática por encima de la tan-

39 Vale la pena mencionar que la discusión de Rees en torno del atomismo de Bacon ignora casi por completo los escritos alegóricos (cf. Rees, 1980, p. 562-3). 
gible en ninguno de sus escritos. Ciertamente, hay que reconocer que en Novum organum Bacon le atribuye a la materia los pliegues (plicae) que son propios de lo pneumático y que, además, concibe que toda la materia es una suerte de continuo cualitativo que va desde lo más pneumático (el éter) hasta lo más tangible (las entrañas de la Tierra), atribuyéndole la principal actividad a la parte pneumática del espectro. Pero incluso aquí la materia tangible sigue proveyendo cohesión y organización a la totalidad de la materia. Entonces, si es verdad que "el instinto dicotomizante es la característica principal de la perspectiva metafísica de Bacon”, como sostiene Rees, resulta necesario que la actividad de la materia pneumática sea tan necesaria como la pasividad de la materia tangible (cf. Rees, 1977, p. 114-5). Pero, siguiendo a Rees, ¿cabe afirmar que la prevalencia de las explicaciones no mecanicistas es una consecuencia directa del rol activo de la materia pneumática? No lo creo, dado que el enfoque no-mecanicista o animista de Bacon respecto del problema del movimiento no es el único compatible con la materia pneumática. Podría haber razonado como Descartes unas décadas después, explicando los movimientos de los espíritus desde una perspectiva mecanicista. Y, de hecho, esa suerte de abordaje mixto (mecanicista y animista) de la materia fue característico de la filosofía natural baconiana en sus distintos momentos más o menos comprometidos con el atomismo.

$\mathrm{Al}$ igual que los espíritus, la materia tangible y sus movimientos son distinguidos en Sylva sylvarum. Bacon no usa los términos "mínima", "partículas mínimas" etc. como los atributos exclusivos de la materia tangible o de la pneumática, sino de ambas. En suma, no encuentro evidencia que indique que, para Bacon, el atomismo y la teoría pneumática de la materia son incompatibles..$^{\circ}$

\section{Conclusión}

A partir de este análisis, se pueden distinguir tres etapas en el atomismo de Bacon. La primera aparece en Cogitationes, donde expresa su apoyo a un atomismo concebido desde un punto de vista instrumental o heurístico, sin decidir si los átomos existen de hecho o no. Los define como las partículas de materia, últimas e iguales, que se mueven en el vacío y que sirven para explicar la sutilidad de la naturaleza. Dos ideas centrales llevan a Bacon a proponer simultáneamente los conceptos de átomo y de materia pneumática en este periodo. En primer lugar, considera que ambos conceptos son condiciones necesarias para explicar los cambios cualitativos (la trasmutación de los cuer-

40 Lemmi (1933, p. 100); Hesse (1983, p. 245); Garner (1970, p. 275) sugieren también que espíritus y átomos no son incompatibles. 
pos), ya que el vacío sólo explica el cambio cuantitativo (mediante contracción y rarefacción). En segundo lugar, entiende que tanto la materia pneumática como los átomos iguales son condiciones necesarias para la constancia del quantum de materia.

La segunda etapa se ve reflejada en los textos alegóricos, donde encontramos las consideraciones de Bacon sobre los átomos más profundamente ontológicas. El átomo es ahora genuinamente considerado como aquello que constituye la partícula más pequeña de la materia. La forma de la resistencia determina su ser, ya que los atributos de movilidad, apetito, dimensionalidad, espacialidad, emanación, eternidad e inmutabilidad emergen de esta resistencia a la aniquilación. Sostiene que los atributos más complejos, por oposición, son efecto de las aglomeraciones atómicas (cf. Gemelli, 1996, p. 163-4).

La tercera y última etapa se pone más en evidencia en el Novum organum, donde Bacon opone los átomos duros-cum-vacío a la materia flexible sin vacío. Las razones que están detrás de este cambio de posición no tienen que ver con la antítesis entre el mecanicismo atomista y el pneumatismo animista, como se ha sostenido. Tal como hemos visto, Bacon siempre concibe que los átomos y la materia pneumática coexisten, y no de una manera antitética..$^{\mathbf{4}}$ La crítica al atomismo que aparece en el Novum organum no está acompañada por la introducción de una teoría de la materia exclusiva o predominantemente pneumática. Las razones de ello son de índole epistemológica y operativa, ya que considera que el átomo, además de ser imperceptible es científicamente improductivo. Los fenómenos naturales se explican mejor mediante el nivel microscópico más complejo de las particulae verae, es decir, a nivel de los esquematismos materiales y sus movimientos (metaesquematismos). En otras palabras, en este último período de su pensamiento, Bacon no niega la existencia del átomo, o al menos no de manera explícita, pero le transfiere todas sus funciones explicativas a los esquematismos.

Klein describe correctamente los esquematismos en términos de la materia tangible y la materia pneumática que surgen de la textura y reconoce en ellos una cierta influencia atomista (cf. Klein, 1997, p. 305-6; Glericuzio, 1984). Pero hay algo más que decir al respecto: tal como Gemelli ha demostrado, el término textura está extraído del vocabulario de Lucrecio (cf. Gemelli, 1996, p. 196-7). A la luz de esto, se puede conjeturar que, para Bacon, los esquematismos son compuestos de partículas mínimas últimas organizadas en distintas formas geométricas, definición en la que sigue a Lucrecio, quien es después de todo una de sus fuentes de inspiración más importantes. Ciertamente sería un error confundir con los átomos las partículas mínimas que se mencionan

4,1 Bacon no es un caso aislado. Varios estudiosos han mostrado que para distintos filósofos de los siglos XVI y xVII las cosmovisiones animistas y las cosmovisiones atomistas no eran incompatibles entre sí (cf. Gregory, 1966; Henry, 1986, p. 371, nota 19; Gemelli, 1996, p. 142, nota 2). 
en Sylva sylvarum y otras obras tardías. Cabe agregar que Bacon presente en su última etapa las partículas mínimas como las últimas unidades epistemológicamente accesibles, no implica necesariamente que niegue la existencia de unidades aún más pequeñas, o de átomos últimos. Más aún, el hecho de que en las Cogitationes coexista la hipótesis atomista con explicaciones basadas en partículas de un nivel más alto es un signo de que Bacon no considera que su perspectiva epistemológica excluya tales supuestos ontológicos últimos. Sin embargo, también es cierto que después del Novum organum no apeló directamente a los átomos para explicar los cambios y acciones naturales.

Desafortunadamente, no hay evidencia textual que nos permita resolver definitivamente la postura final de Bacon acerca de este tema. No obstante, es posible imaginar las consecuencias de cada alternativa posible. Si asumimos que la inutilidad epistemológica de los átomos no implica su rechazo ontológico, la distinción (cf. cuadro 1) entre principio y origen, basada en la polaridad entre átomos y formas, no perdería su valor ontológico. De hecho, conservaría cierta utilidad hermenéutica al echar luz sobre los antecedentes del concepto de forma en el Novum organum, en la medida en que el concepto de materia prima aún funciona como la base material de las formas. Por otra parte, si asumimos que Bacon eventualmente negó la existencia de los átomos, debería concluirse que su explicación alegórica de los principios y orígenes del mundo no podría seguir funcionando. Como consecuencia, la ontología de Bacon en el Novum organum sólo podría dar cuenta del mundo físico actual, pero no podría explicar sus comienzos.

Más allá de cuál conjetura sea la correcta, lo evidente es que las cuestiones relativas a los principios materiales últimos de la materia no tienen importancia en la filosofía tardía de Bacon, porque los átomos ya no tienen un rol causal-operativo. Los átomos, si existen, serían indeterminados y ciegos, y no desempeñarían ningún papel en la explicación de los movimientos de la materia. Antes bien, el origen de tales movimientos se encuentra en los esquematismos materiales.ه

\section{Agradegimientos}

Agradezco al Prof. Christoph Meinel por sus comentarios y a los participantes de la iv International Conference Research: Late Medieval and Early Modern Corpuscular Matter Theory, realizada en la Universidad de St. Andrews (Escocia) en 1996 y organizada por la Foundation for the Intellectual History, por sus comentarios y sugerencias a las versiones preliminares de este artículo. Este artículo es una versión traducida de Manzo, 2001.

Silvia MAnzo

Profesora Adjunta de la Universidad Nacional de La Plata. Investigadora Adjunta del Consejo Nacional de Investigaciones Científicas y Técnicas (Conicet), Argentina. silviamanzo@speedy.com.ar 


\begin{abstract}
AB STRACT
There is no unanimity among recent historians about Francis Bacon's theory of matter. Disagreement exists in particular about Bacon's atomist and animistic ideas. My claim is that although Bacon changed his views on atomism repeatedly, he never rejected it completely. I shall reconstruct Bacon's various opinions in chronological order to establish his final evaluation of atomism and his reasons for it. Because Bacon never held an orthodox atomist matter theory identical with Greek atomism, for this paper I will define atomism in the broadest sense, as a corpuscular matter theory that posits final and indivisible particles. Following this semantic delimitation, two successive Baconian opinions may be distinguished: the first took the atomism to constitute an ontological and causative-operational principle; the second deprived the atom of its causative-operational ability, but did not touch its ontological priority. Furthermore, I will investigate the question of the coexistence of atomism and pneumatism in Bacon's theory, a point that has been discussed in the influential interpretations by Kargon and Rees. However, I shall argue that Bacon did not regard these two doctrines as incompatible.
\end{abstract}

KeYwords $\bullet$ Francis Bacon. Atomism. Pneumatism. Matter theory. Animism. Causality. Void. Alchemy. Motion. Motion of resistance.

\title{
REFERENGIAS BIBLIOGRÁFIGAS
}

Arnim, H. von (Ed.). Stoicorum veterum fragmenta. Leipzig: [s.n.], 1903-1924. 4 v.

Bacon, F. The works of Francis Bacon. London: Longman and Co., 1857-1874. 14, v.

The letters and life of Francis Bacon. London: [s.n.], 1861-74. 7 v.

The Oxford Francis Bacon. Oxford: Oxford University Press, 1996. v. 6.

The new organon. Cambridge: Cambridge University Press, 2000.

Briggs, J. Francis Bacon and the rethoric of nature. Cambridge, Mass.: Harvard University Press, 1989.

Cardanus, H. M. De subtilitate libri XXI. Basileae: [s.n.], 1554 .

Clerricuzio, A. Le trasmutazioni in Bacon e Boyle. In: Fattori, M. (Ed.). Francis Bacon, terminologia e fortuna nell ХИІІ sécolo. Roma: Edizioni dell'Ateneo, 1984. p. 29-42.

Conim bricenses. Commentatoriorum Collegii Conimbricensis Societatis Jesu, in octo libros physicorum Aristotelis Stagiritae. Colonia: Haeredum Lazarus Zetznerus, 1616 [1592].

Carvalho, M. S. Medieval influences in the Coimbra commentaries. An inquiry into the foundations of jesuit education. Patristica et Mediaevalia, 20, p. 19-37, 1999.

EAMON, W. Science and the secrets of nature, books of secrets in medieval and early modern culture. Princeton/ New Jersey: Princeton University Press, 1994.

Epicuro. Opere. Turín: Eunadi, $197^{3}$.

Fатtori, M. Nature semplici in F. Bacon. Nouvelle de la Republique des Lettres, 3, p. 21-33, 1983.

GARner, B. C. Francis Bacon, natalis comes and the mythological tradition. Journal on the Warburg and Courtland Institute, 33, p. 264-91, 1970.

Gatтi, H. Giordano Bruno: the texts in the library of the ninth earl of Northumberland. Journal of the Warburg and Courtland Institute, 4,6, p. 63-77, 1983.

Minimum and maximum, finite and infinite. Bruno and the Northumberland circle. Journal of the Warburg and Courtland Institute, 4, , p. 144,-63, 1985.

Gemelli, B.Aspetti dell'atomismo classico nella filosofia di Francis Bacon enel seicento. Florencia: Leo Olschki, 1996. 
GILbert, W. De mundo nostro sublunari philosophia nova. [s.l.]: Amstelodami, 1661.

Gregory, T. Studi sull'atomismo del seicento. Giornale Critico della Filosofia Italiana , 45, p. 44-63, 1966.

Hannaway, O. The chemists and the world: the didactic origins of chemistry. Baltimore/London: Johns Hopkins University Press, 1975 .

HenRY, J. Occult qualities and the experimental philosophy: active principles in pre-Newtonian matter theory. History of Science, 24, p. 335-81, 1986.

Heronis, A. Spiritualium liber. A Federico Commandino Urbinate, ex graeco, nuperin latinum conversus. Urbini: [s.n.], 157 .

Hesse, M. Francis Bacon. In: O'Connor, D. J. (Ed.). Historia crítica de la filosofía occidental. Barcelona: Paidós, 1983 [1964].v. 2. p. 236-47.

JacQuot, J. Harriot, Hill, Warner and the new philosophy. In: ShirLey, J. W. (Ed.). Thomas Harriot: renaissance scientist. Oxford: Oxford University Press, 1974. p. 107-28.

Jardine, L. Francis Bacon. Discovery and the art of discourse. Cambridge: Cambridge University Press, 1974 .

Kargon, R. H.Atomism in England from Harriot to Newton. Oxford: Clarendon Press, 1966.

KLeIn, U. Experiment, Spiritus un Okkulte qualitäten in der Philosophie Francis Bacons. Philosophia Naturalis, 33, p. 289-314, 1997 .

Lasswitz, K. Geshichte der Atomistik von Mittelalter bis Newton. Darmstadt: Wissenschaftliche Buchgessellschaft, 1963 [1891].

Lemmi, C. W. The classical deities in Bacon. A study in mythological symbolism. Baltimore: The Johns Hopkins University Press, 1933.

Lucrecio. De rerum natura libri sex. Oxford: Clarendon Press, 1947. 3 v.

Lüthy, C.; Murdoch, J. \& Newman, W. (Ed.). Late medieval and early modern corpuscular matter theories. Leiden/Boston/Köln: Brill, 2001.

Macció, M. A proposito dell'atomismo nel Novum organum di Francesco Bacone. Rivista Critica di Storia della Filosofia, 17, p. 187-96, 1962.

Manzo, S. A. Francis Bacon and atomism: a reappraisal. In: Lüthy, G.; Murdoch, J. \& Newman, W. (Ed.). Late medieval and earlymodern corpuscularmatter theories. Leiden/Boston/Köln: Brill, 2001. p. 209-4,3.

O’Connor, D. J. (Ed.). Historia crítica de la filosofía occidental. Barcelona: Paidós, 1983 [1964]. v. 2.

Pabst, B. Atomtheorien des lateinischen Mittelalter. Darmstadt: Wissenschafliche Buchgesselschaft, 1994 .

PAGEL, W. Paracelsus. Basel/New York: Karger, 1982 [1958].

Partington, J. R. A history of chemistry. London/New York: Macmillan, 1961. v. 2.

Patrizi, F. Nova de universis philosophia libris quinquaginta. Venettis: [s.n.], 1583.

Peltonen, M. (Ed.). The Cambridge companion to Bacon. Cambridge: Cambridge University Press, 1996.

Pérez-Estévez, A. La materia, de Avicena a la escuela franciscana. Maracaibo: Ediluz, 1998.

PÉrez-Ramos, A. Francis Bacon's idea of science and the maker's knowledge tradition. Oxford: Oxford University Press, 1988.

Bacon's forms and the maker's knowledge tradition. In: Peltonen, M. (Ed.). The Cambridge companion to Bacon. Cambridge: Cambridge University Press, 1996. p. 99-120.

Rees, G. Francis Bacon's semi-paracelsian cosmology. Ambix, 22, p. 85-101, 1975 .

. Matter theory: a unifying factor in Bacon's natural philosophy. Ambix, 25, p. 110-25, 1977.

. Atomism and 'subtlety' in Francis Bacon's philosophy. Annals of Science, 37, p. 549-71, 1980.

REIF, P. The textbook tradition in natural philosophy, 1600-1650. Journal of the History of Ideas, 3०, p. $17^{-}$ 32,1969 .

Rigaud, S. P. Supplement to Bradley's miscellaneus works. Oxford: Oxford University Press, 1833.

Rossi, P. Francis Bacon: de la magia a la ciencia. Madrid: Alianza, 1990 [1974]. 
Frangis Bacon y el atomismo: una nUeVa eValuación

Rütten, T. Hippokrates im Gespräch, Selbstverlag der Universitäts-und Landesbibliothek un des Institus für Theorie und Geschichte der Medizin der Westfälischen Wilhems-Universität Münster. Münster: Universität Münster, 1993.

Shirley, J. W. (Ed.). Thomas Harriot: renaissance scientist. Oxford: Oxford University Press, 1974.

Telesio, B. De rerum natura Iuxta propria principia libri IX. Neapolis: [s.n.], ${ }_{1} 5^{86 .}$

Urbach, P. Francis Bacon's philosophy of science. La Salle, Ill.: Open Court, 1987.

Viano, C. A. Esperienzia e natura nella filosofia di Francesco Bacone. Rivista di Filosofia, 3, p. 291-313, 1954.

WoLfF, E. Francis Bacon und seine Quellen. Berlin: E. Felber, 1910-1913. 2 v.

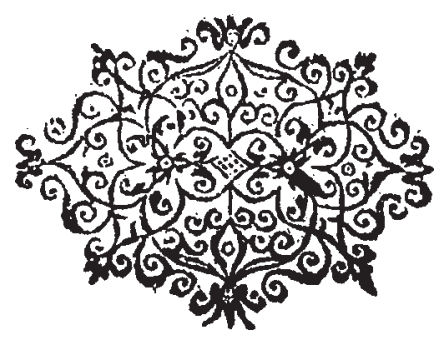

